\title{
Long-term policy evaluation: Application of a new robust decision framework for Iran's energy exports security
}

\author{
Mohammad Alipour * \\ Griffith School of Engineering, Griffith University, Australia \\ Email: Mohammad.Alipour@Griffithuni.edu.au
}

Reza Hafezi

Technology Foresight Group, Department of Management, Science and Technology, Amirkabir University of Technology (Tehran Polytechnic), Tehran, Iran

Futures Studies Research Institute,

Amirkabir University of Technology (Tehran Polytechnic), Tehran, Iran.

Sustainable Energies Group, Office of Sustainability, Amirkabir University of Technology (Tehran Polytechnic), Tehran, Iran.

Email: r.hafezi@aut.ac.ir

\section{Bilal Ervural}

İstanbul Technical University, Industrial Engineering Department, Macka, Istanbul 34367, Turkey

Email: bervural@itu.edu.tr

Mohamad Amin Kaviani

Young Researchers and Elite Club, Shiraz Branch, Islamic Azad University, Shiraz, Iran.

Email: aminkaviani1366@yahoo.com

\section{Özgür Kabak}

İstanbul Technical University, Industrial Engineering Department, Macka, Istanbul 34367, Turkey

Email:kabak@itu.edu.tr

${ }^{*}$ Corresponding author. P.O. Box: 4214. Tel: +610404352223

E-mail address: Mohammad.Alipour@,Griffithuni.edu.au (M. Alipour). 


\title{
Long-term policy evaluation: Application of a new robust decision framework for Iran's energy exports security
}

\begin{abstract}
The objective of this research is to assess long-term energy security policy under uncertain environment. Uncertainty is an integral part of the energy policy analysis in long-term planning, in particular for energy-exporting countries seeking to secure sustainable export revenues. This study proposes a framework to evaluate energy export policy at the strategic level by addressing inherent uncertainties exist in energy-exporting countries. Seven criteria (political, economic, social, technological, legal, environmental, and robustness) are considered to appraise the identified energy export security alternatives. A new hybrid Multi-Criteria Decision-Making (MCDM) model is proposed based on intuitionistic fuzzy sets suitable for uncertain judgments that integrates Intuitionistic Fuzzy Analytic Hierarchy Process (IFAHP) and the Cumulative Belief Degree (CBD) methods. CBD, which is strengthened by IFAHP in determining criteria weights, allows experts to freely evaluate alternatives in various formats and can successfully deal with missing judgments by experts in case of doubt, eligibility or lack of information. Scenario planning is also incorporated into the decision-making process by determining four realistic projections. As a case study, the proposed framework is applied to analyze Iran's energy export security. Results suggest that natural gas has the highest export priority while petroleum products (excluding gasoline) stand last in all scenarios.
\end{abstract}

Keywords: Energy security; Multi-criteria decision making; Cumulative belief degree; Intuitionistic fuzzy analytical hierarchy process; Scenario planning.

\section{Introduction}

Energy is the most fundamental natural resource of Iran's economy. Energy sector constitutes the largest component of the country's economic muscle with more than $30 \%$ of GDP, accounting for $60 \%$ of the total budget. As the world's first- and fourth -largest reserve holder of natural gas (33,721 bn standard cu $\mathrm{m}$ ) and proved oil (158.4 thousand million barrels), respectively [1], along with abundance of diverse renewable energy sources (RES) [2], it is only natural to exploit these massive resources for all-round development. Energy exports have been an inseparable instrument of national policy to bolster economic revenue, which also provides insights into opportunities for advancements in other areas (Fig. 1). The country has long been playing an active role in international energy markets and with its substantial natural reserves, nothing less is expected for the foreseeable future. 


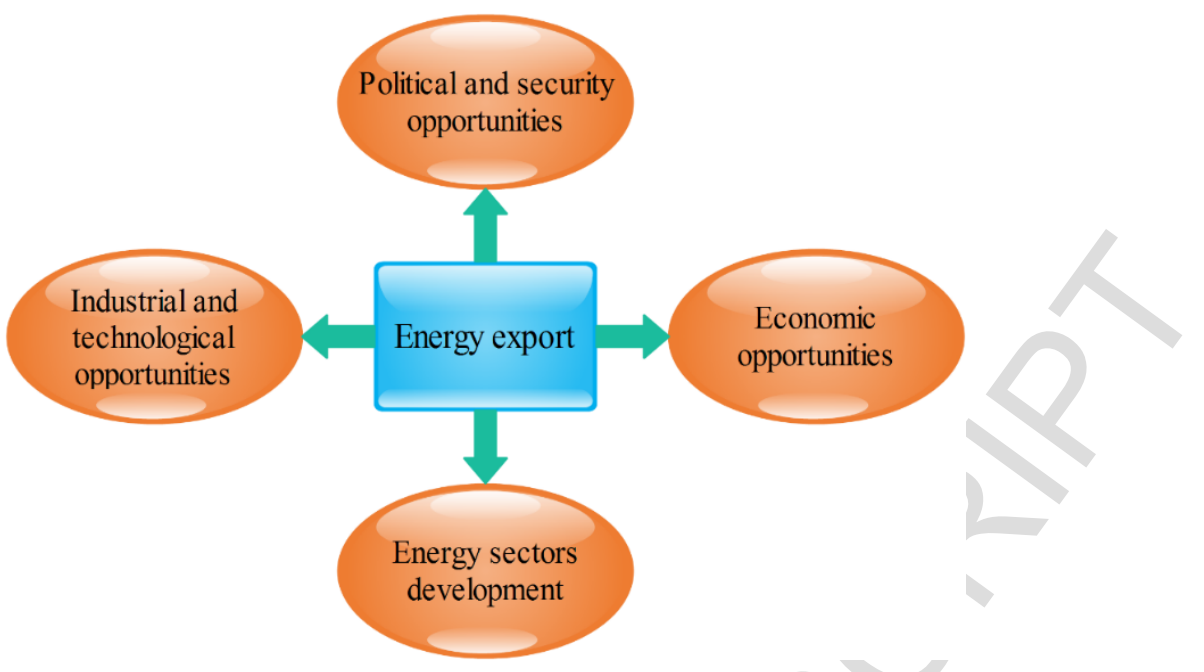

Fig. 1. The strategic importance of EES to Iran.

However, challenges in the energy sector have faced deployment of export options with adverse perceptions over the past two decades (Fig. 2), the latest of which involves the nuclear issue. The current energy outlook is now more vivid after two years of the nuclear agreement in July 2015 between world powers and the country. Efforts in the interim were directed toward restoring the lost share of the oil market to the pre-sanctions level [3]. This was a knee-jerk policy reaction to avoid further consequences of international limitations, a similar case to the nuclear infrastructure expansion during sanctions period (2011-2015). There are also other vast domains of critical uncertainties surrounding the sector; numerous legal constraints, political and geopolitical instability, inefficient economic institutions and governmental structure of the economy are just a handful of problems in this respect [4-6]. These challenges could be expanded through more unstable concepts for the long-term energy exports security (EES) pathways, directing the government to emphasize unsustainable development with a short-term prospect. To tackle these challenges and achieve a comprehensive strategy, this study proposes a robust Multi-Criteria Decision Making (MCDM)-based framework for EES alternatives.

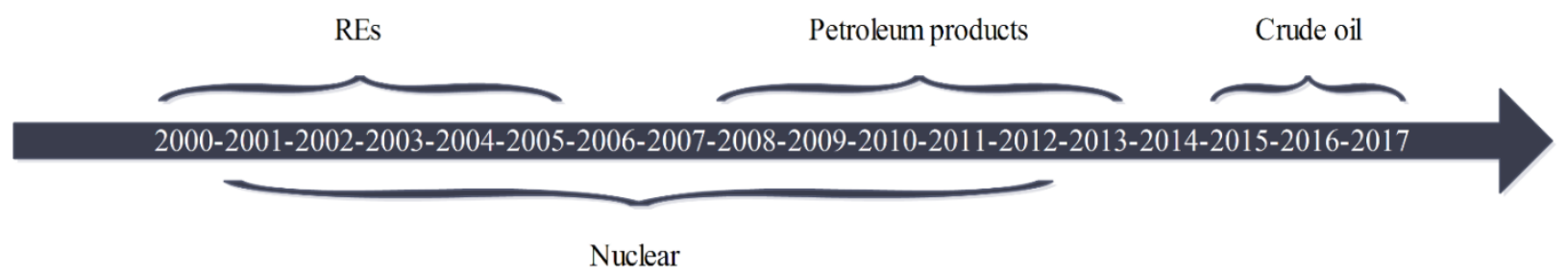

Fig. 2. Bold energy policies affecting Iran's EES over the past two decades. Note that tendency toward one or two energy sources in each period does not indicate less attention to other types, but underlines implementation of new support packages for the potentially long-term policy.

The proposed framework first involves identification of relevant criteria in different categories through political $(\mathrm{P})$, economic $\left(\mathrm{E}_{1}\right)$, social $(\mathrm{S})$, technological $(\mathrm{T})$, legal $(\mathrm{L})$ and environmental $\left(\mathrm{E}_{2}\right)$ (PESTLE) analysis [7] as well as main robustness criteria (PESTLE+R). Plausible scenarios are then generated and used for different modes of MCDM to a better formulation and avoid impulsive policy reactions. Scenario planning in this study describes main characteristics of each projection to further determine the importance of relevant criteria. Incorporation of robustness criteria into the scenario planning is an additive value to the robustness decision-making process. A new hybrid 
intuitionistic-based MCDM model is then developed that seeks to reinvigorate the systematic decision process of the EES planning. It benefits from the Cumulative Belief Degree (CBD) technique developed by Kabak et al. [8] to prioritize export alternatives. The problem of this research comprises primary and secondary energies together with electricity generated from both types. It is a multidimensional problem with several -mainly qualitative- criteria from different aspects where evaluation information is often difficult to predict accurately. The inherent complexity of the energy systems in scenarios is also expanded through significant amount of uncertainties in the context. Under such circumstance, an expert may not possess a sufficient level of knowledge, or have a certain degree of hesitation over the alternative. In addition, an expert with a specific domain of knowledge is ideally ineligible to express opinions on all alternatives and criteria given the lack of competence or expertise. Standard and extended fuzzy MCDM methods entail all information for the evaluation process, which may engender incompetent and inaccurate evaluations. The capability of CBD to deal with these challenges makes it suitable for the problem of this study. The method deals with missing judgments owing to the lack of expertise while effectively works with a degree of hesitancy in indeterminate cases [9]. The method can also capture expert judgments in various formats at different scales, including numerical and qualitative value, 2-tuples, interval values, linguistic terms, hesitant fuzzy and intuitionistic fuzzy sets (IFSs).

Criteria weights in traditional CBD is directly derived through experts' aggregated judgments. This can be further improved by utilizing Intuitionistic Fuzzy Analytic Hierarchy Process (IFAHP) for determining the importance weighs of criteria [10]. IFSs, proposed by Atanassov as an extension of standard fuzzy sets [11], has been incorporated with most of the MCDM methods to enhance their applicability to tackle decision-making problems under uncertainty. IFAHP enables experts to describe the decision-making process more precisely, offering more benefits than the traditional and fuzzy AHP approaches $[10,12]$. Therefore, application of the new hybrid method suitable for heterogeneous judgments is proposed and incorporated with the use of scenario planning, PESTLE and robustness criteria to promote long-term energy policy planning under uncertainty. The aim of this study beyond ranking energy sources for export is to explore a resilient policy structure unaffected by uncertainties and internal/external forces.

The existing literature shows a revived interest in studies that deal with energy security planning. Månsson et al. [13] list main quantitative methods used for evaluating energy security; and several researchers address the use of indicators to measure the various dimensions of energy security $[14,15]$. Scenario planning is a wide-used method for security scholars [16-18] while the use of multi-criteria analyses has been sparse in the area. Worth mentioning are studies of Stirling [19], Lee et al [20], and Karvetski [21]. This study contributes to the existing literature by using and combining these two approaches. On the global scale, demand and supply issues are at the center of energy security strategies for both developed and emerging economies [22]. Internal and external dimensions of energy security angles within the sub-national [23], national [24, 25], and region $[26,27]$ domains are explored to support and analyze future policy direction. However, studying the reverse side, i.e., from export perspective is rather rare. This study seeks to provide insight into an energy exporting country trying to keep its global market share. The literature also deals with economic [28], political [29], legal [30], and environmental [31] aspects in most separate studies. The research integrates all the relevant aspects as well as uncertainties exist in these aspects to cover such a broad field.

The remainder of the research proceeds as follows. Section 2 provides basics of IFS definitions and a short description of IFAHP and CBD methods before introducing the proposed framework. 
The proposed model is applied in section $\underline{3}$ to evaluate EES alternatives in Iran as the case study. Results of the model are provided in section $\underline{4}$. Finally, concluding remarks are summarized in section $\underline{5}$.

\section{Materials and methods}

\subsection{Basic concepts of IFSs}

Definition 1 [32]. Assume $X$ is a non-empty set and $A$ is a subset of $X$, the fuzzy set be introduced as follows:

$$
=\left\{\left\langle x, \mu_{x}(x)\right\rangle \mid x \in X\right\}
$$

Where the fuzzy set membership function of $A^{f}$ is $\mu_{\mathbb{W}}: X \rightarrow[0,1]$ and the membership degree of $x \in X$ is $\mu_{\text {qa }}(x)$.

Definition 2 [11]. Consider $X$ as a non-empty set and $A$ as a subset of $X$. In this situation, the intuitionistic fuzzy set $\widetilde{A}$ is described as:

$$
\widetilde{A}=\left\{\left\langle x, \mu_{\widetilde{A}}(x), \nu_{\widetilde{A}}(x)\right\rangle \mid x \in X\right\}
$$

Where $\mu_{\tilde{A}}: X \rightarrow[0,1]$ and $v_{\widetilde{A}}: X \rightarrow[0,1]$ represent the membership and non-membership function of $x \in X$ in $A$, respectively, and for every $x \in X$ :

$$
0 \leq \mu_{\widetilde{A}}(x)+v_{\widetilde{A}}(x) \leq 1
$$

Consequently, each fuzzy set is considered as a specific case of an IFS and can be displayed as an IFS as follows:

$$
=\left\{\left\langle x, \mu(x), 1-\mu_{1}(x)\right\rangle \mid x \in X\right\}
$$

Definition 3 [33]. Let $\left\{\left\langle x, \mu_{1}(x), 1-\mu_{\text {and }}(x)\right\rangle \mid x \in X\right\}$ be an IFS. $\pi_{\widetilde{A}}(x)$ represents an intuitionistic index of $A$ in $X$ and can be defined as:

$$
\pi_{\widetilde{A}}(x)=1-\mu_{\widetilde{A}}(x)-v_{\widetilde{A}}(x)
$$

$\pi_{\widetilde{A}}(x)$ shows the hesitancy degree of $x$ in $A$ and computes indeterminacy degree of the element $x$ in $A$. According to the theory of triangular fuzzy numbers introduced by Dubois and Prade [34], TIFNs are explained as follows:

Definition 4 [35]. A TIFN $\widetilde{a}=\left\langle(\underline{a}, a, \bar{a}) ; \delta_{\widetilde{a}}, \varepsilon_{\widetilde{a}}\right\rangle$ is a particular IFS associated with an interval $[\underline{a}, \bar{a}]$ where $\underline{a} \leq \bar{a}$. Consider $\delta_{\widetilde{a}}$ as the maximum membership degree and $\varepsilon_{\widetilde{a}}$ as the minimum non-membership degree. Let $\mu_{\widetilde{a}}$ and $\nu_{\widetilde{a}}$ be related to the TIFN $\tilde{a}$ where $\mu_{\widetilde{a}}$ represents the membership function and $v_{\widetilde{a}}$ represents the non-membership function. $\mu_{\widetilde{a}}$ and $\nu_{\widetilde{a}}$ can be defined as: 


$$
\begin{aligned}
& \mu_{\widetilde{a}}= \begin{cases}(x-\underline{a}) \delta_{\widetilde{a}} /(a-\underline{a}) & \text { if } \underline{a} \leq x<a \\
\delta_{\widetilde{a}} & \text { if } x=a \\
(\bar{a}-x) \delta_{\widetilde{a}} /(\bar{a}-a) & \text { if } a<x \leq \bar{a} \\
0 & \text { if } x<\underline{a} \text { or } x>\bar{a}\end{cases} \\
& v_{\widetilde{a}}= \begin{cases}{\left[a-x+(x-\underline{a}) \varepsilon_{\widetilde{a}}\right] /(a-\underline{a})} & \text { if } \underline{a} \leq x<a \\
\varepsilon_{\widetilde{a}} & \text { if } x=a \\
{\left[x-a+(\bar{a}-x) \varepsilon_{\widetilde{a}}\right] /(\bar{a}-a)} & \text { if } a<x \leq \bar{a} \\
1 & \text { if } x<\underline{a} \text { or } x>\bar{a}\end{cases}
\end{aligned}
$$

The terms $\mu_{\widetilde{a}}, v_{\widetilde{a}}, \delta_{\widetilde{a}}$ and $\varepsilon_{\widetilde{a}}$ related to a TIFN are depicted in Fig. 3 .

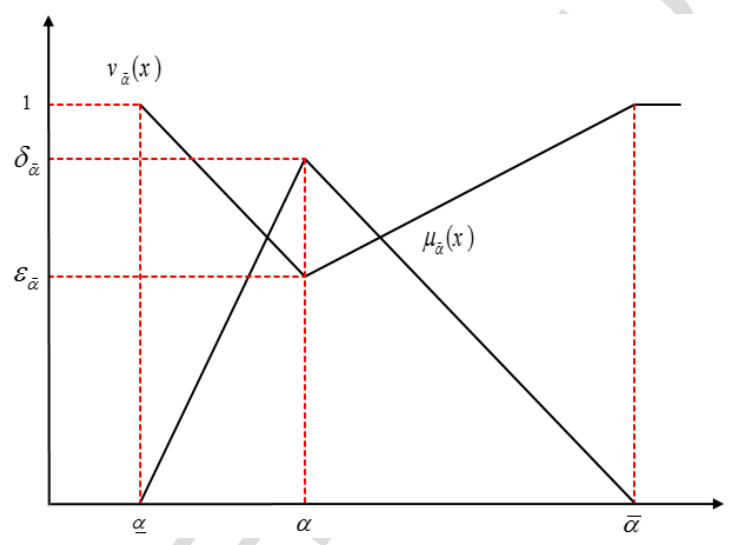

Fig. 3. A TIFN in the form of $\tilde{a}$

\subsection{AHP in the intuitionistic fuzzy environment}

After introducing the AHP method by Saaty [36], the technique has been applied and extended by several researchers. Van Laarhoven \& Pedrycz [37], Chang [38] and Wang et al. [39] extend AHP to the fuzzy environment and present fuzzy AHP models to handle the vagueness in MCDM problems. Recently, AHP has been generalized to the intuitionistic fuzzy environment (e.g., Sadiq \& Tesfamariam [40] and Xu \& Liao [12]). Tavana et al. [10] also propose a new IFAHP model which is developed based on intuitionistic fuzzy preference programming (IFPP) introduced by Mikhailov and Singh [41]. The derived priority vectors by this method need less computational efforts because of using linear programming models. The steps of this approach are explained as follows:

Step 1: Generating hierarchical structure: Assume expert faces an MCDM problem modeled through AHP with $n$ criteria and $a$ alternatives, criteria have a weight set shown by $w$. Similar to the traditional AHP procedures, the hierarchical structure of the decision-making problems is created and criteria, sub-criteria, and alternatives are determined. 
Step 2: Creating comparison matrices applying TIFN: Expert performs pairwise comparisons among criteria by intuitionistic fuzzy data using TIFNs as $\widetilde{a}_{i j}=\left\langle\left(l_{i j}, m_{i j}, u_{i j}\right) ; \delta_{i j}, \varepsilon_{i j}\right\rangle$ where $\delta_{i j}$ and $\varepsilon_{i j}$ are the membership and non-membership degrees of $\tilde{a}_{i j}$. Table 1 shows the TIFNs and their equivalent linguistic terms for experts' judgments.

Table 1. The IFAHP utilized scale [10].

\begin{tabular}{ll}
\hline Extremely strong & $(8,9,9)$ \\
Intermediate & $(7,8,8)$ \\
Very strong & $(6,7,8)$ \\
Intermediate & $(5,6,6)$ \\
Strong & $(4,5,6)$ \\
Intermediate & $(3,3,4)$ \\
Moderately strong & $(1,2,3)$ \\
Intermediate & $(0,1,2)$ \\
Equally strong & $(0,0,1)$ \\
\hline
\end{tabular}

Expert provides a set of interval judgments, which is consistent if there is a priority vector $w=\left(w_{1}, w_{2}, \ldots, w_{n}\right)^{t}$ that satisfies:

$$
l_{i j} \widetilde{x} \frac{w_{i}}{w_{j}} \widetilde{\leq} u_{i j} \quad i=1,2, \ldots, n, j=2,3, \ldots, n, i<j,
$$

where $\widetilde{\leq}$ represents "fuzzy less than or equal to". Each expert provides a set of $m=\frac{1}{2} n(n-1)$ pairwise comparisons and we face $2 m$ fuzzy linear constraints provided that the following membership and non-membership functions are defined and the ratio $\frac{w_{i}}{w_{j}}$ is linear (Eq. (9-10)):

$$
\mu_{\tilde{a}_{i j}}\left(\frac{w_{i}}{w_{j}}\right)= \begin{cases}\left(\frac{w_{i}}{w_{j}}-l_{i j}\right) \delta_{i j} /\left(m_{i j}-l_{i j}\right) & \text { if } l_{i j} \leq \frac{w_{i}}{w_{j}}<m_{i j} \\ \delta_{i j} & \text { if } \frac{w_{i}}{w_{j}}=m_{i j} \\ \left(u_{i j}-\frac{w_{i}}{w_{j}}\right) \delta_{i j} /\left(u_{i j}-m_{i j}\right) & \text { if } m_{i j}<\frac{w_{i}}{w_{j}} \leq u_{i j} \\ 0 & \text { if } \frac{w_{i}}{w_{j}}<l_{i j} \text { or } \frac{w_{i}}{w_{j}}>u_{i j}\end{cases}
$$




$$
v_{\tilde{a}_{i j}}\left(\frac{w_{i}}{w_{j}}\right)= \begin{cases}{\left[m_{i j}-\frac{w_{i}}{w_{j}}+\left(\frac{w_{i}}{w_{j}}-l_{i j}\right) \varepsilon_{i j}\right] /\left(m_{i j}-l_{i j}\right)} & \text { if } l_{i j} \leq \frac{w_{i}}{w_{j}}<m_{i j} \\ {\left[\frac{w_{i}}{w_{j}}-m_{i j}+\left(u_{i j}-\frac{w_{i}}{w_{j}}\right) \varepsilon_{i j}\right] /\left(u_{i j}-m_{i j}\right)} & \text { if } \frac{w_{i}}{w_{j}}=m_{i j} \\ 1 & \text { if } m_{i j}<\frac{w_{i}}{w_{j}} \leq u_{i j} \\ & \text { if } \frac{w_{i}}{w_{j}}<l_{i j} \text { or } \frac{w_{i}}{w_{j}}>u_{i j}\end{cases}
$$

Moreover, $R w \widetilde{\leq} 0$ is a matrix inequality which is the result of using Eq. (8) for deriving all $2 m$ fuzzy linear constraints where the dimension of matrix $R$ is $2 m \times n$, or the following set of fuzzy linear constraints:

$$
R_{k} w \widetilde{\leq} 0, k=1,2, \ldots, 2 m
$$

where $R_{k}$ stands for the $k$-th row of matrix $R$. The term $\mu_{k}$ is also used for indicating the membership function of the $k$-th constraint $R_{k} w \leq 0$.

Step 3: Measuring consistency ratios (CRs): The consistency of the following two crisp matrices is checked to examine the consistency of the fuzzy comparison matrix $\widetilde{A}=\left(\widetilde{a}_{i j}\right)_{i, j=1, \ldots, n}$ whose $i j$-th element is a TFN $\widetilde{a}_{i j}=\left(l_{i j}, m_{i j}, u_{i j}\right)$,

$$
\begin{aligned}
& A^{m}=\left(m_{i j}\right)_{i, j=1, \ldots, n} \\
& A^{g}=\left(\sqrt{u_{i j} \cdot l_{i j}}\right)_{i, j=1, \ldots, n}
\end{aligned}
$$

The judgments of experts are consistent if the CR of both matrices in Eq. (12) is less than 0.1. CR can be computed as:

$$
C R^{m}=C I^{m} / R I
$$

where

$$
\begin{aligned}
& C I^{m}=\left(\lambda_{\max }^{m}-n\right) /(n-1) \\
& \lambda_{\max }^{m}=\frac{1}{n} \sum_{i=1}^{n} \sum_{j=1}^{n} m_{i j}\left(\frac{\omega_{j}^{m}}{\omega_{i}^{m}}\right) \\
& \omega_{i}^{m}=\frac{1}{n} \sum_{j=1}^{n} \frac{m_{i j}}{\sum_{i=1}^{n} m_{i j}}
\end{aligned}
$$

and 
$C R^{g}=C I^{g} / R I$

where

$$
\begin{aligned}
& C I^{g}=\left(\lambda_{\max }^{g}-n\right) /(n-1) \\
& \lambda_{\max }^{g}=\frac{1}{n} \sum_{i=1}^{n} \sum_{j=1}^{n} \sqrt{u_{i j} \cdot l_{i j}}\left(\frac{\omega_{j}^{g}}{\omega_{i}^{g}}\right) \\
& \omega_{i}^{g}=\frac{1}{n} \sum_{j=1}^{n} \frac{\sqrt{u_{i j} \cdot l_{i j}}}{\sum_{i=1}^{n} \sqrt{u_{i j} \cdot l_{i j}}}
\end{aligned}
$$

Step 4: Calculating local weights using IFPP: Through solving the following nonlinear mathematical model (Eq. (15)), the relative weights of all under evaluation criteria and sub-criteria can be computed as:

$\max \theta$

$$
\begin{aligned}
& \alpha-\theta\left(f_{1}-f_{0}\right) \geq f_{0} \\
& \beta+\theta\left(g_{1}-g_{0}\right) \leq g_{1} \\
& m_{i j} w_{j}-w_{i}+\left(w_{i}-l_{i j} w_{j}\right) \varepsilon_{i j}-\beta w_{j}\left(m_{i j}-l_{i j}\right) \leq 0 \\
& w_{i}-m_{i j} w_{j}+\left(u_{i j} w_{j}-w_{i}\right) \varepsilon_{i j}-\beta w_{j}\left(u_{i j}-m_{i j}\right) \leq 0 \\
& \alpha w_{j}\left(m_{i j}-l_{i j}\right)-\left(w_{i}-l_{i j} w_{j}\right) \delta_{i j} \leq 0 \\
& \alpha w_{j}\left(u_{i j}-m_{i j}\right)-\left(u_{i j} w_{j}-w_{i}\right) \delta_{i j} \leq 0 \\
& w_{1}+w_{2}+\cdots+w_{n}=1 \\
& w_{1}, w_{2}, \ldots, w_{n} \geq 0 \\
& i=1,2, \ldots, n ; \quad j=2,3, \ldots, n ; \quad i<j .
\end{aligned}
$$

To solve the above model, first a set of optimization problems for gaining the optimal values of $f_{0}, f_{1}, g_{0}$ and $g_{1}$ need to be solved:

$$
\begin{array}{llll}
f_{0}: \min \alpha & f_{1}: \max \alpha & g_{0}: \min \beta & g_{1}: \max \beta \\
\alpha \leq \mu_{k}\left(R_{k} w\right) & \alpha \leq \mu_{k}\left(R_{k} w\right) & \alpha \leq \mu_{k}\left(R_{k} w\right) & \alpha \leq \mu_{k}\left(R_{k} w\right) \\
\beta \geq v_{k}\left(R_{k} w\right) & \beta \geq v_{k}\left(R_{k} w\right) & \beta \geq v_{k}\left(R_{k} w\right) & \beta \geq v_{k}\left(R_{k} w\right) \\
\sum_{i=1}^{n} w_{i}=1 & \sum_{i=1}^{n} w_{i}=1 & \sum_{i=1}^{n} w_{i}=1 & \sum_{i=1}^{n} w_{i}=1 \\
k=1,2, \ldots, 2 m & k=1,2, \ldots, 2 m & k=1,2, \ldots, 2 m & k=1,2, \ldots, 2 m
\end{array}
$$

Variables $\alpha$ and $\beta$ in Eq. (16) are then computed by:

$$
\alpha=\min \left\{\mu_{1}\left(R_{1} w\right), \mu_{2}\left(R_{2} w\right), \ldots, \mu_{m}\left(R_{m} w\right)\right\}
$$




$$
\beta=\max \left\{v_{1}\left(R_{1} w\right), v_{2}\left(R_{2} w\right), \ldots, v_{m}\left(R_{m} w\right)\right\}
$$

Step 5: Computing global weights: Global weights of all sub-criteria is computed by:

global weight of "subcriterion" =

(local weight of "subcriterion") $\times($ local weight of "criterion")

\subsection{Cumulative Belief Degree}

The CBD approach was originally developed by Kabak and Ruan [42] based on fuzzy linguistic terms and belief structure in the evaluation of nuclear safeguards. It has been further applied to MCDM problems, energy policy evaluation [43] prioritization of energy sources [8] and measuring sustainable development [44]. The approach has recently been extended to cope with heterogeneous information in group MCDM problems [9]. CBD is underpinned by its ability to deal with the information given in different formats by transforming input data to belief degrees. It enables handling incomplete input data when there is a lack of information or expertise. The approach also enriches the interpretation of the results by providing a final score as a distribution of linguistic levels.

In this study, the belief structure is used to represent the belief of experts in their evaluations of alternatives with respect to criteria through fuzzy linguistic terms. Let $S=\left\{s_{k}\right\}, k \in\{0, \ldots, K\}$ be a finite and totally ordered term set. Any label, $s_{k}$, represents a possible value of a linguistic variable. The semantics of the finite term set $\mathrm{S}$ is given by fuzzy numbers, which are defined in the $[0,1]$ interval, and by their membership functions. In this study, a seven-term set $S=\left\{s_{k}\right\}, k \in\{0, \ldots, 6\}$ is used (Table 2). The steps of the approach are described as follows.

Table 2. Linguistic terms for the ratings.

\begin{tabular}{lll}
\hline Linguistic term & Label & Triangular fuzzy sets \\
\hline$s_{1}$ & Very Poor (VP) & $(0,0,0.167)$ \\
$s_{2}$ & Poor (P) & $(0,0.167,0.333)$ \\
$s_{3}$ & Medium Poor (MP) & $(0.167,0.333,0.5)$ \\
$s_{4}$ & Fair (F) & $(0.333,0.50,0.667)$ \\
$s_{5}$ & Medium Good (MG) & $(0.50,0.667,0.833)$ \\
$s_{6}$ & Good (G) & $(0.667,0.833,1)$ \\
$s_{7}$ & Very Good (VG) & $(0.833,1,1)$ \\
\hline
\end{tabular}

In the EES problem, experts $(e=1, \ldots, E)$ evaluate alternatives $(i=1, \ldots, I)$ with respect to criteria $(j=1, \ldots, J)$. The importance weights of criteria $\left(w_{j}{ }^{n}\right)$ and experts $\left(\lambda_{e}\right)$ are also specified in the previous phases. The performance ratings for alternatives with respect to each sub-criterion $\left(x_{i j}^{e}\right)$ are provided to construct the decision matrix for each expert and scenario $(n=1, \ldots, N)$. Experts may prefer to state performance values with respect to their individual criteria set.

In the particular application, experts use three different formats to make judgments. These judgments are transformed into belief structures according to the transformation formulae defined as follows: 
Transformation of direct value assignments into the belief structure: If the evaluation is made with a direct value assignment on a $0-\mathrm{C}$ scale ( 0 is the lower bound and $\mathrm{C}$ is the upper bound of the scale, e.g. 0-100 Scale), the membership values of the assignment related to each linguistic term are equal to belief degrees. Taking $\mu_{s_{k}}, k=0, \ldots, K$, as the membership functions of linguistic terms $s_{k}$, the belief structure related to an assignment $\vartheta$ is found as [42]:

$$
B(\vartheta)=\left\{\left(\mu_{s_{k}}(\vartheta), s_{k}\right), \quad k=0, \ldots, K\right\}
$$

As an example, consider a seven-term linguistic set with triangular membership functions as in Fig. 4. When the expert evaluation is $\vartheta=12$ on a $0-20$ scale, the corresponding belief structure would be $\left\{\left(0.4, s_{3}\right),\left(0.6, s_{4}\right)\right\}$, where $\varepsilon=0.4$ and $\delta=0.6$ are the membership values of $\vartheta=12$ in FSs $\mathrm{s}_{3}$ and $\mathrm{s}_{4}$, respectively.

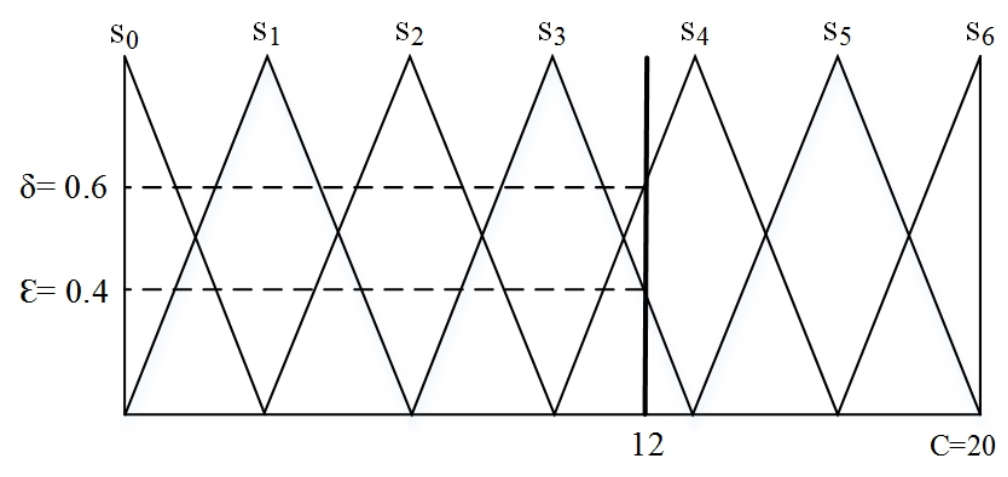

Fig. 4. Transformation of an assignment to the belief structure.

Transformation of Linguistic terms to the belief structure: If an expert makes an evaluation with a linguistic term $s_{k}$, then the related belief structure is formed as:

$$
\mathrm{B}=\left\{\left(1, s_{k}\right)\right\}
$$

For instance, consider a seven-term linguistic set with triangular membership functions. If the evaluation of the expert is linguistic $\left(s_{3}\right)$, it is represented by the belief structure $\left\{\left(1, s_{3}\right)\right\}$.

Transformation of intuitionistic fuzzy sets to the belief structure: If the evaluation is made with an IFS, $I(\mu, \vartheta, \pi)$ (defined in Eq. (1-5)), they are transformed into belief structure using [9]:

$$
B(I(\mu, \vartheta, \pi))=\left\{\left(\mu_{s_{k}}\left(\frac{\mu}{\mu+\vartheta}\right) *(1-(\pi * \sigma)), s_{k}\right), \quad k=0, \ldots, K\right\}
$$

where $\sigma \in[0,1]$ is a coefficient reflecting the indeterminacy. As an example, if the expert evaluation is an IFS $(0.5,0.3,0.2)$ and $\sigma=0.8$, then the corresponding belief structure would be $B$ $(I(0.5,0.3,0.2))=\left\{\left(0.21, s_{3}\right),\left(0.63, s_{4}\right)\right\} \quad$ where $0.21(=0.25 *(1-(0.2 * 0.8)))$ and 0.63 $(=0.75 *(1-(0.2 * 0.8)))$ are calculated based on the membership degree of $I(0.5,0.3,0.2)$ in fuzzy sets $s_{3}$ and $s_{4}$, respectively (Fig. 5). 


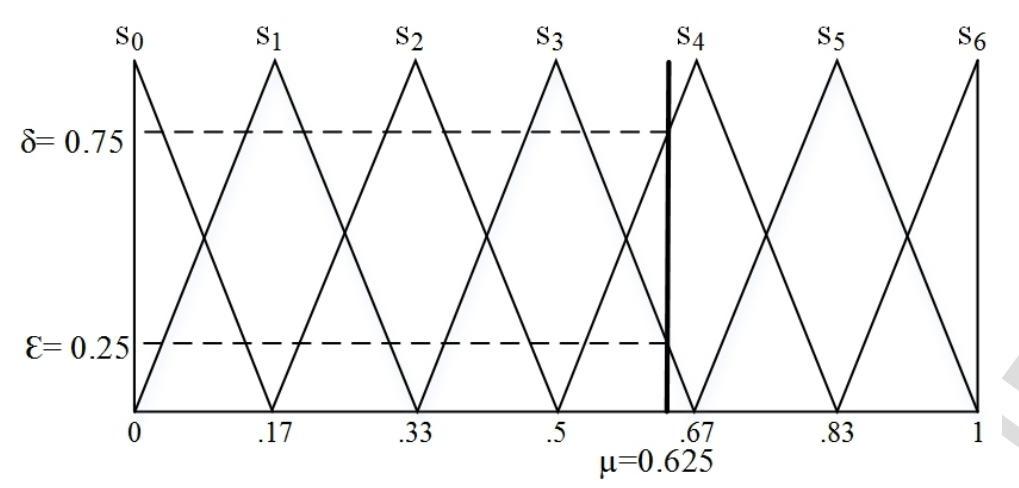

Fig. 5. Transformation of an intuitionistic fuzzy set evaluation to the belief structure.

Obtained evaluations are transformed to belief structures before they are aggregated for each expert and alternative. Note that the importance degree of criteria is determined for each scenario while experts do not make evaluations for sub-criteria. Therefore, the weights of criteria for each expert value are revised to take only the criteria expert made a judgment into account:

$$
v_{j}^{n, e}=\frac{w_{j}^{n}}{\sum_{l \in P_{e}} w_{l}^{n}}
$$

where $P_{e}$ is the set of criteria that expert $e$ makes an evaluation. Then the total belief degree of the alternative for each expert at $s_{k}$ level can be found by the weighted sum of belief degrees of experts with respect to criteria for $s_{k}$. The belief structure of expert $e$ related to alternative $i$ is formed as:

$$
\mathrm{B}_{i}^{e}=\left\{\left(\beta_{i}^{e k}{ }^{e} s_{k}\right), k=0, \ldots, K\right\}, \forall e, \forall i
$$

where $\beta_{i}^{e k}$ denotes the belief degree of the expert $e$ for alternative $i$ at $s_{k}$ level and is calculated as:

$$
\beta_{i}^{e k}=\frac{\sum_{j} w_{j}^{e} \beta_{i j}^{e k}}{\left(\sum w_{j}^{e} \mid j, e, \Sigma_{k} \beta_{i j}^{e k}>0\right)}
$$

The cumulative belief structure for expert $e$ 's evaluations of alternative $i$ can be defined as:

$$
\begin{aligned}
& \mathrm{C}_{i}^{e}=\left\{\left(\gamma_{i}^{e k}, s_{k}\right), k=0, \ldots, K\right\}, \forall e, \forall i, \\
& \gamma_{i}^{e k}=\sum_{p=k}^{K} \beta_{i}^{e p}
\end{aligned}
$$

\subsubsection{Aggregation of the expert evaluations for each alternative}

Expert evaluations are now aggregated for each alternative to get a final CBD. Suppose each expert has an importance value with respect to their expertise and experience given as $\lambda_{e} \cdot \gamma_{i}^{k}$, total performance of an alternative at $s_{k}$ linguistic level is calculated by:

$$
\mathrm{C}_{i}=\left\{\left(\gamma_{i}^{k}, s_{k}\right), k=0, \ldots, K\right\}, \forall i,
$$




$$
\gamma_{i}^{k}=\sum_{e=1}^{E} \lambda_{e} \gamma_{i}^{e k}
$$

To compare the final CBDs of alternatives, the aggregated score approach and linguistic-cut approach are used $[8,9]$. The former assigns a single score to each alternative for direct ranking while the latter provides a result for a certain satisfaction level. Therefore, different results for different satisfaction levels can be generated for robustness and sensitivity analysis.

The aggregated score approach assigns expectation values for the linguistic terms for aggregation. Suppose $\varphi_{k}$ indicates an expectation value for the linguistic term $s_{k}$, and then the aggregated score $\left(A S_{i}\right)$ for each alternative, the total expectation can be found by [9]:

$$
A S_{i}=\left(\sum_{k=0}^{K-1} \varphi_{k}\left(\gamma_{i}^{k}-\gamma_{i}^{k+1}\right)\right)+\varphi_{i} \gamma_{i}^{K} \quad \forall i
$$

If no other weighting scheme is suggested, expectation values can be considered as $\varphi_{k}=k, k$ $=0, \ldots \mathrm{K}$.

Linguistic-cut approach provides a rank ordering of alternatives according to a certain satisfaction level $\left(s_{k}\right)$ of the expert or the final decision maker. CBD at $s_{k}$ level is considered the total belief degrees of greater or equal terms to the related linguistic term. It gives a threshold level that is related to the satisfaction of the performance of an alternative according to a criterion. As an example, suppose a seven-term linguistic set, $s_{4}$ (medium good) level, is set as the threshold level. It represents belief degrees for the performance of alternatives to at least "medium good" level (i.e., the sum of belief degrees of $s_{4}, s_{5}, s_{6}$ ). Linguistic cut level of an alternative $i$ at $s_{k}$ level is calculated as:

$$
L C_{i}^{k}=\gamma_{i}^{k}
$$

\subsection{The proposed model}

The proposed framework contains four fundamental phases (Fig. 6): (I) formulating the problem, collecting alternatives and identifying criteria, (II) generating future scenarios, (III) applying IFAHP to obtain criteria weights, and (IV) implementing CBD to prioritize alternatives. Experts chosen for their knowledge in the related field are brought together in an expert panel to carry out the proposed framework. The first phase comprises the establishment of objectives and the decision context. Before arranging the panel, available options were specified and their corresponding criteria and sub-criteria were identified through literature review and PESTLE+R analysis. The online PESTLE questionnaire proceeded as follows: A list of potential parameters (in six categories: political, economic, social, technological, legal and environmental) was sent to the participants from universities and researchers in the energy industry via email and they were requested to return the survey within a given date range. The determined parameters and robustness criteria identified in the literature were then finalized by the experts in the panel.

In phase II, a literature review is performed to select suitable scenarios, and if non-existent, new projections are developed by the experts. Characteristics of the determined scenarios are then extracted to facilitate understanding critical drivers, and subsequently, produce more precise evaluations. The output of the PESTLE+R analysis in phase I and scenarios in phase II are used in phase III to assess the importance of criteria using IFAHP. First, a hierarchical structure of the problem is structured. Experts make pairwise comparisons for each criterion and sub-criterion of 
the main scenario (the one describing the current trend) using the scale given in Table 1. They determine how main criteria would vary in other scenarios. Consistency ratios are tested to ascertain satisfaction of the pairwise comparison matrices. Using TIFNs, a degree of membership and a degree of non-membership is assigned to each one of the performed evaluations. Individual judgments are aggregated by an optimization model based on the fuzzy preference programming method presented by Mikhailov [45]. The outcome of this evaluation with sub-criteria weights in IFAHP delivers new global weights for scenarios.

In phase IV, experts utilize identified alternatives and criteria (phase I), scenarios (phase II), and criteria and sub-criteria weights (phase III) to make evaluations on alternatives. CBD aggregates these evaluations that are performed in different formats. Firstly, these inputs are transformed into the belief structures. The criteria values of each expert are aggregated using the criteria weights found in the previous phase and utilized to compute the CBDs. Then, the relative importance of experts is used to aggregate experts' evaluations. Finally, collective preferences are computed using both aggregated score and linguistic-cut approaches to compare alternatives. By analyzing the results of these two methods over several levels, the best option is selected and the alternatives are ranked in descending order. 


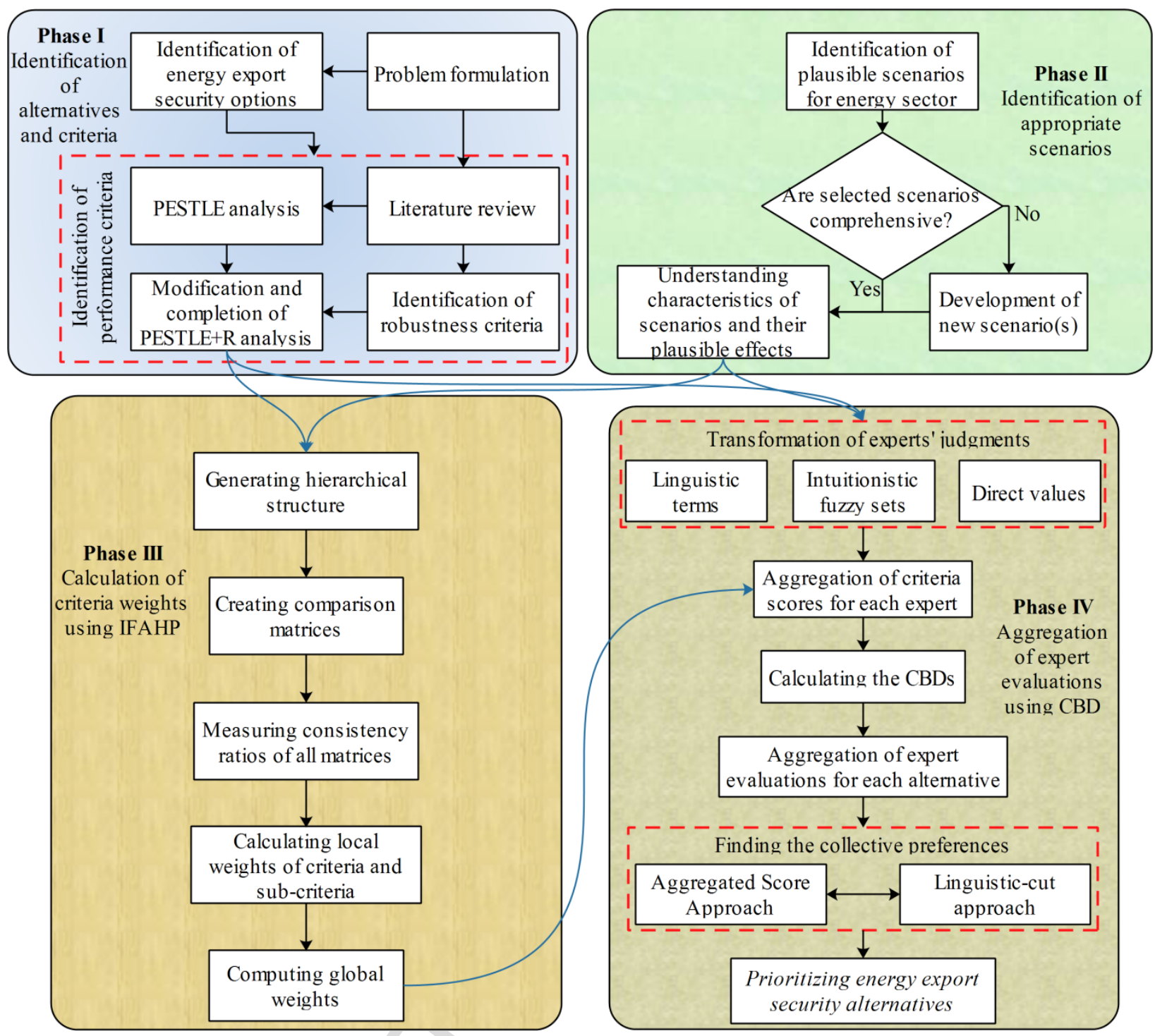

Fig. 6. Methodological phases of the proposed framework for EES.

\section{Application of the proposed model}

This study develops an integrated intuitionistic scenario-based MCDM model to explore EES alternatives for Iran. Investigating various dimensions of energy security requires the participation of experts from different knowledge disciplines. Thus, a twelve-member expert panel comprising energy researchers from universities, technologists, authorities within the government and futurists was constructed to carry out the evaluation process. They were weighted into three groups based on their expertise: Senior (0.1351), intermediate (0.0925), and junior (0.0437) [46]. Experts were requested to (a) select exportable energy items; (b) modify and finalize relevant criteria and subcriteria identified through PESTLE $+\mathrm{R}$ analysis; (c) extract scenarios for Iran's energy sector; (d) conduct pairwise comparisons to obtain weights of criteria (for all scenarios) and sub-criteria (for the main scenario); and (e) make judgments to prioritize the items. 


\subsection{Energy items for export}

Iran's energy-based economy heavily relies on energy export revenues, with more than $82 \%$ of income coming from this sector. Efforts to raise exports' rate have been affected by increasing energy intensity where consumption rate is experiencing a continuous growth; its primary energy consumption escalated from 177.5 in 2005 to 270.7 Mtoe $^{1}$ in 2016 and electricity generation enhanced more than 2.3-fold in the interim [47]. Over the last years, counter actions like "Iranian targeted subsidy plan" strived to slow down this upward trend. However, the desire for higher exports revenues pushes forward the country's plan to focus more closely on the sector. To this end, new oil and gas fields were developed and alternative energies (RES and nuclear) saw deployment [48].

Not all these resources like coal have the production capacity though. Thus, EES alternatives need to be selected based on their proved reserve, marketability, and long-term export capability. Consequently, it seems essential to involve policymakers in the evaluation process of possible alternatives and policy tendencies to extract the most appropriate energy resources. Following the objectives of this study, experts opted for crude oil and natural gas as the current two most easilyaccessible primary energies. The exports of electricity generated from both primary and secondary resources (RES, natural gas, coal and nuclear) have escalated over the past few years and may attract more attention in the future. Petroleum products alternative (including kerosene, gas oil, LPG, residuals, distillates) is another growing option as the current second-biggest energy export option after oil. Gasoline has recently found its place among the most demanded consuming resources in the country and -independently from petroleum products- makes the list. The categorization and choose of these five items (petroleum products, crude oil, electricity, gasoline, and natural gas) by the experts sought to make them reasonably comparable and proportionate.

Table 3 provides details on these alternatives, indicating that exports of all items are currently on the rise.

Table 3. Details on Iran's EES choices.

\begin{tabular}{|c|c|c|c|c|c|c|}
\hline Alternative & $\begin{array}{l}\text { Exports in } 2016 \\
\text { (per day) [49] }\end{array}$ & $\begin{array}{c}\text { Change } \\
16 / 15 \\
(\%)\end{array}$ & $\begin{array}{c}\text { Change in } \\
\text { values of } \\
\text { exports } 16 / 15\end{array}$ & $\begin{array}{l}\text { World } \\
\text { export } \\
\text { ranking \# }\end{array}$ & $\begin{array}{l}\text { Current target } \\
\text { customers }\end{array}$ & $\begin{array}{l}\text { Future target } \\
\text { customers }\end{array}$ \\
\hline $\begin{array}{l}\text { Petroleum } \\
\text { products } \\
\text { (including } \\
\text { gasoline) }\end{array}$ & $\begin{array}{l}0.897 \\
\text { (million barrels) }\end{array}$ & 74.6 & $\begin{array}{c}+20,993 \\
\text { (million \$; } \\
\text { excluding } \\
\text { electricity) }\end{array}$ & 9 & $\begin{array}{c}\text { Iraq, } \\
\text { Afghanistan, } \\
\text { China and } \\
\text { India }\end{array}$ & $\begin{array}{c}\text { Broader } \\
\text { international } \\
\text { markets }\end{array}$ \\
\hline
\end{tabular}

${ }^{1}$ Million Tonnes of Oil Equivalent 


\begin{tabular}{llccccc} 
Crude oil & $\begin{array}{l}1,921.7 \\
\text { (million barrels) }\end{array}$ & 77.7 & 7 & $\begin{array}{c}\text { International } \\
\text { markets }\end{array}$ & $\begin{array}{c}\text { International } \\
\text { markets }\end{array}$ \\
Electricity & $1500\left(10^{9}\right.$ watts $)$ & 50 & 70 & Neighbors & Neighbors \\
Natural gas & $8,567\left(10^{6} \mathrm{~m}^{3}\right)$ & 0.3 & 23 & Neighbors & $\begin{array}{c}\text { Neighbors; } \\
\text { Central Asia } \\
\text { and Europe }\end{array}$ \\
\hline
\end{tabular}

\subsection{Identification of criteria}

The process of identifying criteria was built on literature survey and online PESTLE analysis. An initial list of potential drivers from literature review was handed to the participants involved in the energy sector. PESTLE analysis employed for easier identification and classification of all effective factors in main categories. Participants were asked to estimate the relevance of the selected criteria on a 1-10 scale. A threshold of the scores assigned by twenty-six responds was determined by the average of the grades. Parameters with the rate above the threshold were passed to the experts for further modification: so that the sub-criteria cover broader concepts as much as possible, and to merge those which are over-detailed. Experts also specified main robustness factors derived from literature, to form a total of seven criteria and twenty-four sub-criteria (Table 4).

Table 4. Identified criteria and their descriptions through literature review and PESTLE+R analysis.

\begin{tabular}{|c|c|c|c|}
\hline Criteria & Sub-criteria & References & Comment \\
\hline Political $\left(\mathrm{X}_{1}\right)$ & $\begin{array}{l}\text { Changes in national energy } \\
\text { policies }\left(\mathrm{X}_{11}\right) \\
\text { Foreign dependency }\left(\mathrm{X}_{12}\right) \\
\text { Political risks }\left(\mathrm{X}_{13}\right) \\
\text { Potential export opportunities/ } \\
\text { risks }\left(\mathrm{X}_{14}\right)\end{array}$ & $\begin{array}{c}{[15,50,51]} \\
{[52-54]} \\
{[15,55]} \\
{[16,56,57]}\end{array}$ & $\begin{array}{l}\text { On investment and cutting-edge technology. } \\
\text { Return of sanctions and regional tensions. } \\
\text { Expansion or loss of market share. }\end{array}$ \\
\hline \multirow[t]{2}{*}{ Economic $\left(\mathrm{X}_{2}\right)$} & $\begin{array}{l}\text { Bargaining power }\left(\mathrm{X}_{21}\right) \\
\text { Branding and client royalty } \\
\left(\mathrm{X}_{22}\right)\end{array}$ & $\begin{array}{l}{[58]} \\
\text { Expert opinion }\end{array}$ & $\begin{array}{l}\text { Promoting bargaining power in the energy market. } \\
\text { Establishing a continued presence in the market. }\end{array}$ \\
\hline & $\begin{array}{l}\text { Energy price }\left(\mathrm{X}_{23}\right) \\
\text { Investment risk }\left(\mathrm{X}_{24}\right) \\
\text { Transportation and delivery } \\
\left(\mathrm{X}_{25}\right)\end{array}$ & $\begin{array}{l}{[59,60]} \\
{[61,62]}\end{array}$ & $\begin{array}{l}\text { The rate of changes in energy prices that affecting } \\
\text { profitability and strategic directions. } \\
\text { Uncertainty over payback period. } \\
\text { Safe, reliable, and on-time delivery system with } \\
\text { least logistic cost. }\end{array}$ \\
\hline \multirow[t]{2}{*}{ Social $\left(\mathrm{X}_{3}\right)$} & $\begin{array}{l}\text { Social acceptability \& } \\
\text { benefits }\left(\mathrm{X}_{31}\right)\end{array}$ & {$[21,50,59]$} & $\begin{array}{l}\text { Social attitudes (e.g., knowledge, adaptability, } \\
\text { anxiety, trust, enjoyment, social influence, etc.) } \\
\text { towards accepting or tolerating differences } \\
\text { and diversity. }\end{array}$ \\
\hline & Societal effects $\left(\mathrm{X}_{32}\right)$ & {$[30,50]$} & $\begin{array}{l}\text { Job opportunities/elimination and changes in } \\
\text { demographic distribution. }\end{array}$ \\
\hline \multirow[t]{2}{*}{ Legal $\left(\mathrm{X}_{4}\right)$} & $\begin{array}{l}\text { Availability of insurance, } \\
\text { guarantees, and incentives } \\
\left(\mathrm{X}_{41}\right)\end{array}$ & {$[14,63,64]$} & $\begin{array}{l}\text { Availability of international insurance for } \\
\text { transporting energy sources. }\end{array}$ \\
\hline & $\begin{array}{l}\text { Conformance with } \\
\text { international and client }\end{array}$ & Expert opinion & $\begin{array}{l}\text { Compliance with international environmental, } \\
\text { safety and adapting to consumer standards. }\end{array}$ \\
\hline
\end{tabular}


standards and installation

limitations/characteristics

$\left(\mathrm{X}_{42}\right)$

Governance $\left(\mathrm{X}_{43}\right)$

Tariff lags $\left(\mathrm{X}_{44}\right)$

Environmental Emissions $\left(\mathrm{X}_{51}\right)$

$\left(\mathrm{X}_{5}\right) \quad$ Environmental risks $\left(\mathrm{X}_{52}\right)$

Technological Availability of services $\left(\mathrm{X}_{61}\right)$ $\left(\mathrm{X}_{6}\right)$

Robustness Feasibility and operability

$\left(\mathrm{X}_{7}\right) \quad\left(\mathrm{X}_{71}\right)$

Flexibility $\left(\mathrm{X}_{72}\right)$

Resilience $\left(\mathrm{X}_{73}\right)$
$[15,50,65]$ National policy orientation in terms of foreign affairs, domestic energy basket, and energy economic policies.

Expert opinion To promote optimal consumption pattern and extend sustainable development.

$[25,66]$ Comprising $\mathrm{CO}_{2}, \mathrm{CO}, \mathrm{SO}_{2}, \mathrm{NO}_{\mathrm{x}}$.

$[67,68]$ Impact on natural ecosystem, land use, and noise.

Expert opinion Guarantee availability of further supports and services.

$[14,56,67]$ Ensuring sufficient capability for the long-term planning.

$[56,59]$ Rate and type of energy use for domestic consumption.

$[69,70]$ Potential growth in distribution networks.

$[25,71,72]$ Limits and circumstances within which energy supply is satisfactorily operable.

$[67,71,72]$ Capability to adapt to changes in the uncertain environment.

$[25,72,73]$ Ability to survive changes despite severe impact.

\subsection{Scenarios}

The first alternative future (Reference scenario - I) was developed by experts which describes current set of policies and market trends. This scenario assumes that natural gas production attains its maximum rate in the mid-run period, instead, additional investment arise to maintain the production level at its highest rate. Social pressures given the high unemployment rate persuade governors to shift development projects to the higher job creation opportunities such as refinery industries. In this scenario, international obligations on $\mathrm{CO}_{2}$ reduction motivate the development of RES-related development programs although the lack of sufficient technology does not deliver much progress. Based on the Reference scenario, stifling economic isolation is expected to be amplified; however, the government hopes to take counter-actions to cover lost oil revenues with emerging natural gas markets.

Looking into Iran's energy scenarios to select, development of most trajectories goes back before lifting international sanctions in 2015 [2, 71, 74-76], whereas few studies specifically devoted to the post-sanction period such as Alipour et al. [77]. Two projections (Superego meets stability - II and After the storm - III) are adopted from this research since they cover all related areas and could be used as generalized scenarios for the entire energy sector.

The possibility of returning sanctions is a significant uncertainty that has not yet been scrutinized in previous studies. This is taken into account in All coming back - IV scenario. This projection emphasizes on unstable relations between Iran and western powers. This backward step raised by a radical shift in foreign policy leaves the oil sector willing to renovate its aging fields in the lurch. The new upstream projects will result in delays while major production from other 
fields is effectively spent on rising domestic consumption. Similarly, natural gas related projects will be suspended and REs remain undeveloped. It is expected that in such a situation Iran will face domestic energy demand shock especially in the case of electricity and energy-intensive industries such as steel and cement.

A summary of characteristics and features of these scenarios are illustrated in Table 5 and Fig. 7. All scenarios were projected for the 2030 horizon.

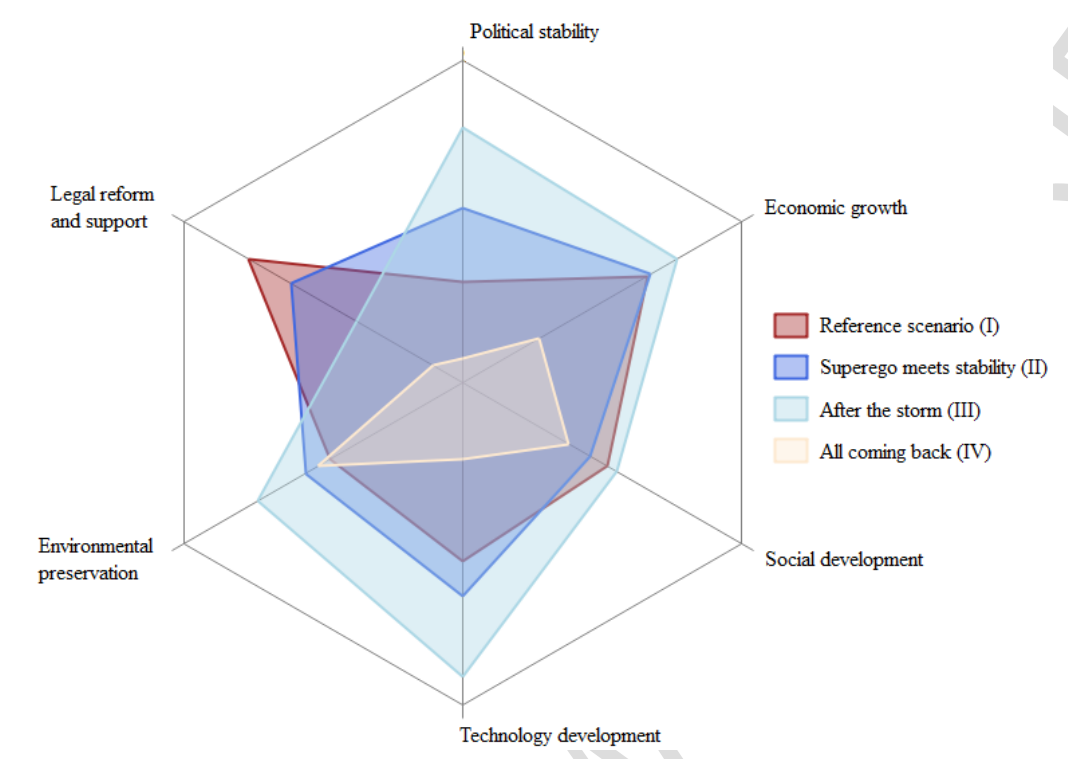

Fig. 7. Six main policy tendencies for Iran's energy scenarios.

Table 5. Characteristics of the scenarios.

\begin{tabular}{|c|c|c|c|c|}
\hline \multirow[b]{2}{*}{ Characteristics } & \multicolumn{3}{|c|}{ Scenarios } & \multirow[b]{2}{*}{$\begin{array}{l}\text { All coming } \\
\text { back (IV) }\end{array}$} \\
\hline & $\begin{array}{l}\text { Reference } \\
\text { scenario (I) }\end{array}$ & $\begin{array}{l}\text { Superego meets } \\
\text { stability (II) }\end{array}$ & $\begin{array}{l}\text { After the storm } \\
\text { (III) }\end{array}$ & \\
\hline Energy production trend & Slight growth & $\begin{array}{c}\text { Advanced project } \\
\text { developments }\end{array}$ & Slight growth & $\begin{array}{l}\text { Maintain the } \\
\text { status quo }\end{array}$ \\
\hline Energy consumption trend & $\mathrm{BAU}^{*}$ & BAU $^{*}$ & Slight decline & Increasing \\
\hline Energy efficiency & Low & Decent & High & Inefficient \\
\hline Technology promotion & Slight growth & $\begin{array}{c}\text { Transferring } \\
\text { updated } \\
\text { technology }\end{array}$ & $\begin{array}{l}\text { Transferring } \\
\text { updated } \\
\text { technology }\end{array}$ & Stalled \\
\hline $\begin{array}{l}\text { General sale/supply policy direction } \\
\text { (crude retail/refined products) }\end{array}$ & Both & Both & Both & Crude \\
\hline RE deployment & Low & Medium & High & Stalled \\
\hline Foreign investments & Medium & High & High & Medium \\
\hline Degree of international collaboration & Medium & Medium & High & Low \\
\hline Influence of environmental concerns & Medium & Medium & High & Low \\
\hline Technological dependency & Medium & High & High & Low \\
\hline Investment sensitivity & Medium & High & High & Medium \\
\hline $\begin{array}{l}\text { Existence of various suppliers/ energy } \\
\text { sources }\end{array}$ & Medium & Medium & Medium & Low \\
\hline
\end{tabular}

${ }^{*}$ Business as usual 


\subsection{IFAHP calculations}

The hierarchy structure of the problem is constructed following the determination of the criteria, sub-criteria, and alternatives. Experts were then asked to make pairwise comparisons in an intuitionistic fuzzy environment using TIFNs indicated in Table 1. In the second step, pairwise comparison matrices were created and experts made their judgments on the main criteria (for each of the four scenarios, separately) and sub-criteria (for the Reference scenario). All answers were aggregated using Mikhailov fuzzy preference programming method [45]. Table 6 demonstrate pairwise comparisons of the criteria for the Reference scenario. Sub-criteria pairwise comparisons for this scenario are performed accordingly.

Table 6. Pairwise comparisons among criteria in the Reference scenario.

\begin{tabular}{cccccccc}
\hline Criteria & $\mathrm{X}_{1}$ & $\mathrm{X}_{2}$ & $\mathrm{X}_{3}$ & $\mathrm{X}_{4}$ & $\mathrm{X}_{5}$ & $\mathrm{X}_{6}$ & $\mathrm{X}_{7}$ \\
\hline $\mathrm{X}_{1}$ & $(1,1,1)$ & $(0.65,1.06,1.54)$ & $(1.08,1.56,2.06)$ & $(1.63,2.05,2.67)$ & $(0.65,1.06,1.54)$ & $(0.31,0.44,0.59)$ & $(0.48,0.66,0.8) ;$ \\
& $(1.08,1.56,2.06)$ & $(1,6,0.2$ & $; 0.6,0.3$ & $; 0.4,0.6$ & $; 0.3,0.7$ & $; 0.6,0.4$ & $0.7,0.3$ \\
$\mathrm{X}_{2}$ & $; 0.6,0.2$ & $(1,1,1)$ & $(1.63,2.05,2.67)$ & $(1.08,1.56,2.06)$ & $(0.31,0.44,0.59)$ & $(0.48,0.66,0.8) ;$ & $(0.31,0.44,0.59)$ \\
& $(0.65,1.06,1.54)$ & $(0.48,0.66,0.8) ;$ & $; 0.7,0.3$ & $; 0.3,0.7$ & $; 0.6,0.3$ & $0.6,0.3$ & $; 0.7,0.3$ \\
$\mathrm{X}_{3}$ & $; 0.6,0.3$ & $0.7,0.3$ & $(1,1,1)$ & $(1.08,1.56,2.06)$ & $(1.63,2.05,2.67)$ & $(0.65,1.06,1.54)$ & $(0.65,1.06,1.54)$ \\
& $(0.48,0.66,0.8) ;$ & $(0.65,1.06,1.54)$ & $(0.65,1.06,1.54)$ & $; 0.6,0.2$ & $; 0.4,0.6$ & $; 0.3,0.7$ & $; 0.3,0.7$ \\
$\mathrm{X}_{4}$ & $0.4,0.6$ & $; 0.3,0.7$ & $; 0.6,0.2$ & $(1,1,1)$ & $(1.08,1.56,2.06)$ & $(0.48,0.66,0.8) ;$ & $(0.48,0.66,0.8) ;$ \\
& $(1.08,1.56,2.06)$ & $(2.09,2.75,3.08)$ & $(0.48,0.66,0.8) ;$ & $(0.65,1.06,1.54)$ & $; 0.6,0.2$ & $0.4,0.6$ & $0.4,0.6$ \\
$\mathrm{X}_{5}$ & $; 0.3,0.7$ & $; 0.6,0.3$ & $0.4,0.6$ & $; 0.6,0.2$ & $(1,1,1)$ & $(0.31,0.44,0.59)$ & $(0.31,0.44,0.59)$ \\
& $(2.09,2.75,3.08)$ & $(1.63,2.05,2.67)$ & $(1.08,1.56,2.06)$ & $(1.63,2.05,2.67)$ & $(2.09,2.75,3.08)$ & $; 0.7,0.3$ & $; 0.6,0.2$ \\
$\mathrm{X}_{6}$ & $; 0.6,0.4$ & $; 0.6,0.3$ & $; 0.3,0.7$ & $; 0.4,0.6$ & $; 0.7,0.3$ & $(1,1,1)$ & $(0.65,1.06,1.54)$ \\
& $(1.63,2.05,2.67)$ & $(2.09,2.75,3.08)$ & $(1.08,1.56,2.06)$ & $(1.63,2.05,2.67)$ & $(2.09,2.75,3.08)$ & $(1.08,1.56,2.06)$ & $; 0.6,0.3$ \\
$\mathrm{X}_{7}$ & $; 0.7,0.3$ & $; 0.7,0.3$ & $; 0.3,0.7$ & $; 0.4,0.6$ & $; 0.6,0.2$ & $; 0.6,0.3$ & $(1,1,1)$ \\
\hline
\end{tabular}

Next, the CRs of all matrices were calculated using Eq. (13-14) after providing pairwise comparisons. LINGO 11.0 was utilized for performing consistency rate analysis. As indicated in Table 7, all the eight comparison matrices exhibit an acceptable consistency rate. For example, the software returned $C R^{m}=0.026<0.1$ and $C R^{g}=0.092<0.1$ as results for the main criteria matrix.

Table 7. CRs of matrices in the Reference scenario.

\begin{tabular}{lcc}
\hline Comparison matrices & $\mathrm{CR}^{\mathrm{m}}$ & $\mathrm{CR}^{\mathrm{g}}$ \\
\hline Main criteria & 0.026 & 0.092 \\
sub-criteria of $\mathrm{X}_{1}$ & 0.019 & 0.066 \\
sub-criteria of $\mathrm{X}_{2}$ & 0.024 & 0.089 \\
sub-criteria of $\mathrm{X}_{3}$ & 0.018 & 0.046 \\
sub-criteria of $\mathrm{X}_{4}$ & 0.013 & 0.068 \\
sub-criteria of $\mathrm{X}_{5}$ & 0.015 & 0.045 \\
sub-criteria of $\mathrm{X}_{6}$ & 0.021 & 0.074 \\
sub-criteria of $\mathrm{X}_{7}$ & 0.15 & 0.041 \\
\hline
\end{tabular}

Step four involves obtaining local weights of sub-criteria through Eq. (15) by solving the IFPP model. In the last step, Eq. (19) computed the global weights of sub-criteria; as for $\mathrm{X}_{11}$, for instance:

$$
\begin{aligned}
\text { global weight of } " X_{11} " & =\left(\text { local weight of } " X_{11} "\right) \times\left(\text { local weight of } " X_{1} "\right) \\
& =\quad 0.160 \times 0.138 \\
& =0.022
\end{aligned}
$$


The calculated global weights of sub-criteria for the Reference scenario are summarized in Table 8. Similar to the above-mentioned calculations, the whole weights of criteria and sub-criteria for the other three scenarios were calculated (as shown in Table 9 and Fig. 8).

Table 8. Weights of criteria \& sub-criteria for the Reference scenario (I).

\begin{tabular}{ccccc}
\hline Criteria & $\begin{array}{c}\text { Global weights } \\
\text { of criteria }\end{array}$ & Sub-criteria & $\begin{array}{c}\text { Local weights of } \\
\text { sub-criteria }\end{array}$ & $\begin{array}{c}\text { Global weights } \\
\text { of sub-criteria }\end{array}$ \\
\hline \multirow{3}{*}{$\mathrm{X}_{1}$} & \multirow{2}{*}{0.138} & $\mathrm{X}_{11}$ & 0.16 & 0.022 \\
& & $\mathrm{X}_{12}$ & 0.29 & 0.040 \\
& & $\mathrm{X}_{13}$ & 0.18 & 0.025 \\
& & $\mathrm{X}_{14}$ & 0.37 & 0.051 \\
$\mathrm{X}_{2}$ & \multirow{2}{*}{0.098} & $\mathrm{X}_{21}$ & 0.13 & 0.013 \\
& & $\mathrm{X}_{22}$ & 0.17 & 0.017 \\
& & $\mathrm{X}_{23}$ & 0.18 & 0.018 \\
$\mathrm{X}_{3}$ & \multirow{2}{*}{0.066} & $\mathrm{X}_{24}$ & 0.31 & 0.030 \\
& & $\mathrm{X}_{25}$ & 0.21 & 0.021 \\
& & $\mathrm{X}_{31}$ & 0.31 & 0.020 \\
$\mathrm{X}_{4}$ & \multirow{2}{*}{0.048} & $\mathrm{X}_{32}$ & 0.69 & 0.046 \\
& & $\mathrm{X}_{41}$ & 0.25 & 0.012 \\
$\mathrm{X}_{5}$ & \multirow{2}{*}{0.057} & $\mathrm{X}_{42}$ & 0.19 & 0.009 \\
& & $\mathrm{X}_{43}$ & 0.38 & 0.018 \\
$\mathrm{X}_{6}$ & \multirow{2}{*}{0.242} & $\mathrm{X}_{44}$ & 0.18 & 0.009 \\
& & $\mathrm{X}_{51}$ & 0.33 & 0.019 \\
& & $\mathrm{X}_{52}$ & 0.66 & 0.038 \\
$\mathrm{X}_{7}$ & \multirow{2}{*}{0.351} & $\mathrm{X}_{61}$ & 0.09 & 0.022 \\
& & $\mathrm{X}_{62}$ & 0.35 & 0.085 \\
& & $\mathrm{X}_{64}$ & 0.20 & 0.048 \\
\hline
\end{tabular}

Table 9. Criteria and sub-criteria weights for scenarios II-IV.

\begin{tabular}{|c|c|c|c|c|c|c|c|}
\hline \multirow[b]{2}{*}{ Criteria } & \multicolumn{3}{|c|}{ Criteria weights } & \multicolumn{4}{|c|}{ Global weights of sub-criteria } \\
\hline & $\begin{array}{c}\text { Superego } \\
\text { meets } \\
\text { stability (II) }\end{array}$ & $\begin{array}{l}\text { After the } \\
\text { storm (III) }\end{array}$ & $\begin{array}{l}\text { All coming } \\
\text { back (IV) }\end{array}$ & $\begin{array}{l}\text { Sub- } \\
\text { criteria }\end{array}$ & $\begin{array}{l}\text { Superego } \\
\text { meets } \\
\text { stability (II) }\end{array}$ & $\begin{array}{l}\text { After the } \\
\text { storm (III) }\end{array}$ & $\begin{array}{c}\text { All coming } \\
\text { back (IV) }\end{array}$ \\
\hline \multirow[t]{4}{*}{$\mathrm{X}_{1}$} & 0.065 & 0.058 & 0.489 & $\mathrm{X} 11$ & 0.010 & 0.009 & 0.073 \\
\hline & & & & $\mathrm{X} 12$ & 0.019 & 0.017 & 0.152 \\
\hline & & & & $\mathrm{X} 13$ & 0.012 & 0.011 & 0.068 \\
\hline & & & & $\mathrm{X} 14$ & 0.024 & 0.021 & 0.196 \\
\hline \multirow[t]{5}{*}{$\mathrm{X}_{2}$} & 0.373 & 0.308 & 0.0635 & $\mathrm{X} 21$ & 0.041 & 0.040 & 0.006 \\
\hline & & & & $\mathrm{X} 22$ & 0.071 & 0.059 & 0.013 \\
\hline & & & & $\mathrm{X} 23$ & 0.067 & 0.037 & 0.011 \\
\hline & & & & $\mathrm{X} 24$ & 0.112 & 0.108 & 0.020 \\
\hline & & & & $\mathrm{X} 25$ & 0.082 & 0.065 & 0.014 \\
\hline \multirow[t]{2}{*}{$\mathrm{X}_{3}$} & 0.036 & 0.056 & 0.0515 & $\mathrm{X} 31$ & 0.014 & 0.019 & 0.019 \\
\hline & & & & X32 & 0.022 & 0.037 & 0.032 \\
\hline \multirow[t]{4}{*}{$\mathrm{X}_{4}$} & 0.269 & 0.037 & 0.026 & X41 & 0.078 & 0.011 & 0.008 \\
\hline & & & & X42 & 0.046 & 0.005 & 0.004 \\
\hline & & & & X43 & 0.105 & 0.014 & 0.010 \\
\hline & & & & X44 & 0.040 & 0.007 & 0.004 \\
\hline \multirow[t]{2}{*}{$\mathrm{X}_{5}$} & 0.035 & 0.136 & 0.016 & X51 & 0.013 & 0.044 & 0.005 \\
\hline & & & & X52 & 0.022 & 0.092 & 0.011 \\
\hline \multirow[t]{3}{*}{$\mathrm{X}_{6}$} & 0.153 & 0.387 & 0.079 & X61 & 0.017 & 0.031 & 0.008 \\
\hline & & & & X62 & 0.043 & 0.124 & 0.025 \\
\hline & & & & X63 & 0.040 & 0.085 & 0.014 \\
\hline
\end{tabular}




\begin{tabular}{llllllll}
\hline & & & & $X 64$ & 0.054 & 0.147 & 0.032 \\
\hline$X_{7} 0.069$ & 0.018 & 0.275 & $X 71$ & 0.017 & 0.005 & 0.072 \\
& & & $X 72$ & 0.030 & 0.007 & 0.107 \\
& & & $X 73$ & 0.022 & 0.006 & 0.096 \\
\hline
\end{tabular}

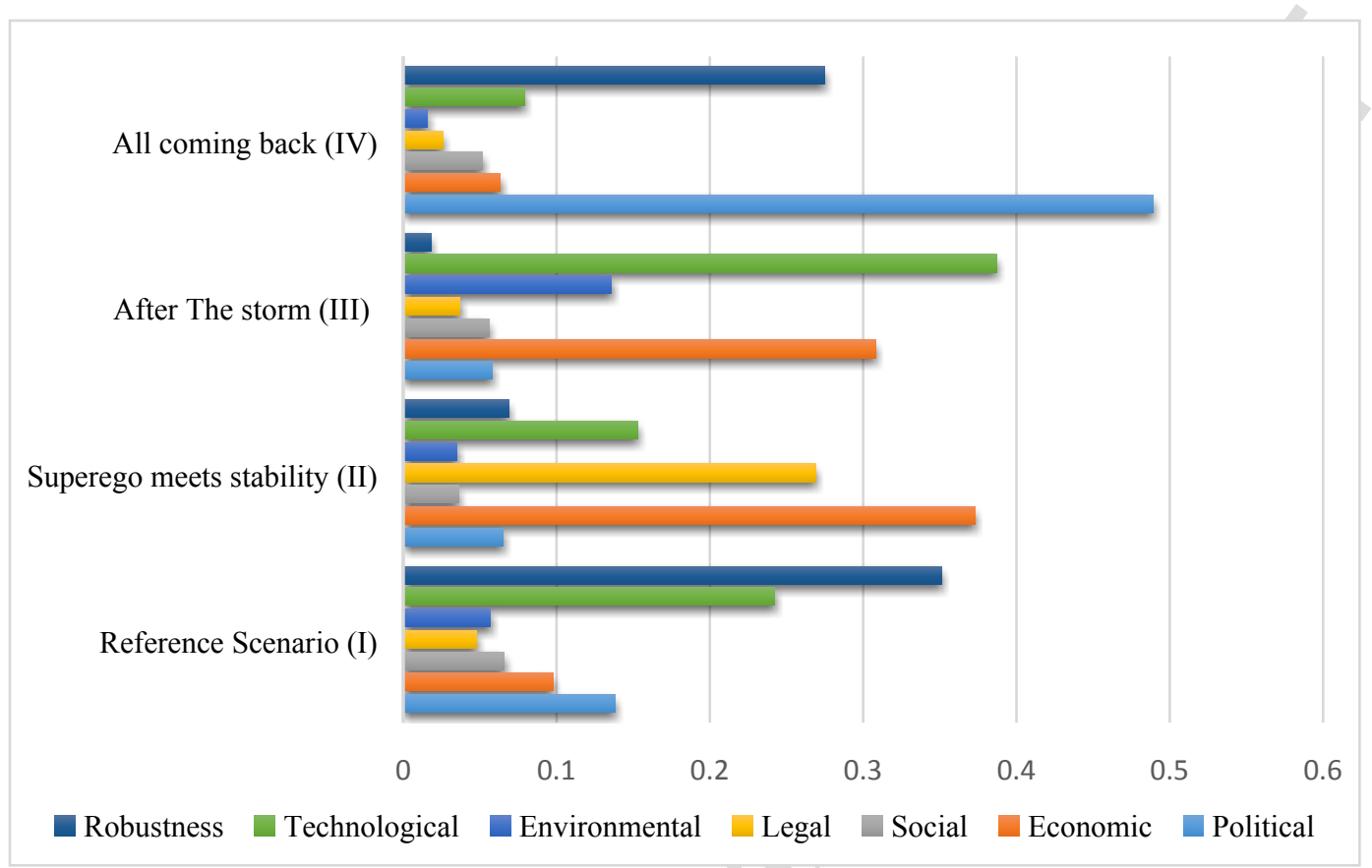

Fig. 8. A scenario comparison on the weights of main criteria.

Under the Reference scenario, robustness is the dominant factor in prioritizing energy export alternatives according to the experts' opinion. This reveals a high probability of change in the current situation as well as the need for flexibility and agility against new conditions. Technology is another substantial factor in the relatively stable settings (scenarios I\&III); with less emphasis, it is still important under other scenarios. In general, social, legal and environmental while show low sensitivity, play an inconsequential role in EES decisions in the Reference scenario. This more or less implies for other scenarios except for Superego meets stability (II) where legal stands as the second major factor after economic. Political instability highlights the role of political factor based on experts' judgments; this is reflected in All coming back (IV). The higher is the political stability in Superego meets stability (II), the more important is the economic criterion. High technology development and economic growth (see Fig. 7) in this projection is also correlated with less emphasis on technology factor, but still important for economic.

\subsection{CBD calculations}

In this section, EES alternatives are evaluated and prioritized through CBD. The expert panel made evaluations using the preferred scale to prioritize items with respect to the sub-criteria. To collect opinions, a questionnaire was designed, in which experts may use different evaluation formats to collect the opinions effectively. Experts may prefer not to make a judgment on a subcriterion given the lack of information or lack of expertise.

In the problem, experts 1-7, 11 and 12 expressed their preferences in IFSs, experts 8-9 in the defined fuzzy linguistic sets (Table 2), and expert 10 in numerical assignments on a 0-20 scale. To 
give the idea of experts' evaluations, evaluations of experts 2 and 9 are given in Table 10. Experts made evaluations according to their own criteria set. For instance; expert 2 did not make any evaluation on four criteria $\left(\mathrm{X}_{41}, \mathrm{X}_{44}, \mathrm{X}_{71}\right.$, and $\left.\mathrm{X}_{73}\right)$ given lack of information while expert 9 evaluated all sub-criteria. Notice that experts' evaluations are the same for all scenarios. The difference of the scenarios rises from the weights of the criteria that are found in the previous step.

Table 10. Evaluations of experts 2 and 9.

\begin{tabular}{|c|c|c|c|c|c|c|c|c|c|c|}
\hline \multirow{2}{*}{$\begin{array}{l}\text { Sub } \\
\text { criteria }\end{array}$} & \multicolumn{5}{|c|}{ Expert 2 - Intuitionistic fuzzy set } & \multicolumn{5}{|c|}{ Expert $9-7$-term fuzzy linguistic set } \\
\hline & $\begin{array}{l}\text { Petroleum } \\
\text { products }\end{array}$ & Crude oil & Electricity & Gasoline & Natural gas & $\begin{array}{c}\text { Petroleum } \\
\text { products }\end{array}$ & $\begin{array}{c}\text { Crude } \\
\text { oil }\end{array}$ & Electricity & Gasoline & $\begin{array}{c}\text { Natural } \\
\text { gas }\end{array}$ \\
\hline $\mathrm{X}_{11}$ & $(0.1,0.9)$ & $(0.4,0.3)$ & $(0.7,0.15)$ & $(0.65,0.3)$ & $(0.65,0.3)$ & $\mathrm{G}$ & $\mathrm{P}$ & $\mathrm{P}$ & MG & VP \\
\hline $\mathrm{X}_{12}$ & $(0.4,0.55)$ & $(0.5,0.35)$ & $(0.4,0.6)$ & $(0.3,0.5)$ & $(0.7,0.15)$ & VG & VP & MP & $\mathrm{P}$ & VP \\
\hline $\mathrm{X}_{13}$ & $(0.05,0.9)$ & $(0.7,0.3)$ & $(0.7,0.3)$ & $(0.65,0.2)$ & $(0.8,0.1)$ & G & VP & G & MP & $\mathrm{F}$ \\
\hline $\mathrm{X}_{14}$ & $(0.05,0.8)$ & $(0.7,0.1)$ & $(0.6,0.1)$ & $(0.3,0.5)$ & $(0.8,0.1)$ & VG & $\mathrm{P}$ & G & VG & $\mathrm{P}$ \\
\hline $\mathrm{X}_{21}$ & $(0.3,0.2)$ & $(0.1,0.3)$ & $(0.4,0.5)$ & $(0.15,0.4)$ & $(0.4,0.4)$ & G & $\mathrm{P}$ & G & VG & VG \\
\hline $\mathrm{X}_{22}$ & $(0.3,0.7)$ & $(0.8,0.1)$ & $(0.3,0.6)$ & $(0.4,0.6)$ & $(0.4,0.4)$ & VG & VP & VG & $\mathrm{G}$ & $\mathrm{G}$ \\
\hline $\mathrm{X}_{23}$ & $(0.1,0.5)$ & $(0.8,0.1)$ & $(0.4,0.2)$ & $(0.6,0.15)$ & $(0.7,0.1)$ & VG & MP & VG & G & $\mathrm{G}$ \\
\hline $\mathrm{X}_{24}$ & $(0.4,0.6)$ & $(0.3,0.6)$ & $(0.6,0.2)$ & $(0.7,0.1)$ & $(0.65,0.25)$ & G & $P$ & VG & G & VG \\
\hline $\mathrm{X}_{25}$ & $(0.4,0.4)$ & $(0.4,0.5)$ & $(0.8,0.1)$ & $(0.4,0.4)$ & $(0.7,0.1)$ & MG & $\mathrm{F}$ & VG & F & MG \\
\hline$X_{31}$ & $(0.2,0.7)$ & $(0.8,0.15)$ & $(0.9,0.05)$ & $(0.5,0.4)$ & $(0.8,0.05)$ & VG & $\mathrm{P}$ & VG & G & $\mathrm{F}$ \\
\hline $\mathrm{X}_{32}$ & $(0.1,0.8)$ & $(0.8,0.05)$ & $(0.4,0.4)$ & $(0.7,0.25)$ & $(0.7,0.1)$ & $\mathrm{MG}$ & MP & VG & G & F \\
\hline $\mathrm{X}_{41}$ & - & - & - & - & - & $\mathrm{F}$ & VG & VP & $\mathrm{G}$ & $\mathrm{P}$ \\
\hline $\mathrm{X}_{42}$ & $(0.4,0.5)$ & $(0.9,0.05)$ & $(0.2,0.7)$ & $(0.5,0.3)$ & $(0.35,0.45)$ & MG & MG & $\mathrm{VP}$ & VG & VP \\
\hline $\mathrm{X}_{43}$ & $(0.6,0.15)$ & $(0.6,0.2)$ & $(0.4,0.55)$ & $(0.8,0.2)$ & $(0.7,0.1)$ & $\mathrm{G}$ & VG & $\mathrm{P}$ & $\mathrm{G}$ & VP \\
\hline $\mathrm{X}_{44}$ & - & - & - & - & & G & $\mathrm{G}$ & $\mathrm{VP}$ & $\mathrm{G}$ & VP \\
\hline $\mathrm{X}_{51}$ & $(0.4,0.5)$ & $(0.5,0.45)$ & $(0.3,0.6)$ & $(0.8,0.05)$ & $(0.8,0.15)$ & F & $\mathrm{F}$ & VG & MP & $\mathrm{F}$ \\
\hline $\mathrm{X}_{52}$ & $(0.8,0.1)$ & $(0.5,0.5)$ & $(0.5,0.3)$ & $(0.7,0.2)$ & $(0.25,0.65)$ & $\mathrm{P}$ & $\mathrm{P}$ & VG & $\mathrm{F}$ & MP \\
\hline $\mathrm{X}_{61}$ & $(0.3,0.6)$ & $(0.65,0.2)$ & $(0.4,0.5)$ & $(0.4,0.3)$ & $(0.8,0.15)$ & $\mathrm{F}$ & MP & VP & $\mathrm{F}$ & VP \\
\hline $\mathrm{X}_{62}$ & $(0.7,0.2)$ & $(0.8,0.15)$ & $(0.4,0.6)$ & $(0.15,0 . .8)$ & $(0.7,0.1)$ & VG & VG & $\mathrm{P}$ & VG & VP \\
\hline $\mathrm{X}_{63}$ & $(0.5,0.3)$ & $(0.4,0.5)$ & $(0.7,0.25)$ & $(0.7,0.15)$ & $(0.4,0.45)$ & $\mathrm{G}$ & $\mathrm{F}$ & VP & $\mathrm{F}$ & VP \\
\hline $\mathrm{X}_{64}$ & $(0.8,0.15)$ & $(0.9,0.05)$ & $(0.7,0.15)$ & $(0.8,0.15)$ & $(0.8,0.1)$ & $\mathrm{F}$ & MP & VP & MP & MP \\
\hline $\mathrm{X}_{71}$ & - & - & - & & - & VP & VP & VG & $\mathrm{G}$ & VP \\
\hline $\mathrm{X}_{72}$ & $(0.1,0.8)$ & $(0.4,0.5)$ & $(0.8,0.2)$ & $(0.4,0.55)$ & $(0.8,0.15)$ & VP & VP & $\mathrm{G}$ & $\mathrm{F}$ & $\mathrm{VP}$ \\
\hline$X_{73}$ & - & - & - & - & - & $\mathrm{P}$ & VP & VG & MG & $\mathrm{G}$ \\
\hline
\end{tabular}

To aggregate the evaluations using $\mathrm{CBD}$ approach, at the first step, different formats of expert evaluations are transformed to the belief structure. To this end, a seven-term linguistic set $S=\left\{s_{k}\right\}$ ,$k \in\{0, \ldots, 6\}$ is used where the meanings are assigned as given in Table 2. Numerical evaluations are transformed into the belief structure based on Eq. (20). As an example, numerical assignment of expert 10 for crude oil under criterion $\mathrm{X}_{11}$, which is equal to 8 in $0-20$ interval, is transformed to belief structure $B_{2}, \mathrm{X}_{11}^{10}=\left\{\left(0.60, s_{2}\right)\left(0.40, s_{3}\right)\right\}$ using Eq. (20) and TFN defined in Fig. 4).

The evaluations of experts 8 and 9 are made directly with linguistic variables and are transformed into a belief structure according to Eq. (21) based on the linguistic term sets defined in Table 2. As an example, expert 9's evaluation of gasoline with respect to criterion $X_{73}$, which is equal to medium good (MG), is transformed into a belief structure as $B_{4, X_{73}}^{9}=\left\{\left(1, s_{4}\right)\right\}$.

The evaluations of experts 1-7, 11 and 12 which are made with IFSs are transformed into a belief structure according to Eq. (22). For example, evaluation of expert 2 for petroleum products 
with respect to criterion $X_{21}$, which is equal to $I(0.3,0.2,0.5)$, is transformed into a belief structure as:

$$
B\left(I(0.3,0.2,0.5)=\left\{(0.40 *(1-(0.5 * 0.8))), s_{3}\right),\left(0.60 *(1-(0.5 * 0.8)), s_{4}\right)\right\}=\left\{\left(0.24, s_{3}\right),\left(0.36, s_{4}\right)\right\}
$$

Therefore, the related belief structure is $B_{1}, \mathrm{x}_{21}^{2}=\left\{\left(0.24, s_{3}\right),\left(0.36, s_{4}\right)\right\}$. Using similar calculations, the belief structures of expert 2 for petroleum products alternative are calculated as given in Table 11.

Table 11. Belief structures of expert 2 for petroleum products.

\begin{tabular}{llccccccc}
\hline $\begin{array}{l}\text { Sub- } \\
\text { criteria }\end{array}$ & \multirow{2}{*}{ Assignment } & \multicolumn{7}{c}{ Belief Degrees } \\
\cline { 3 - 9 } $\mathrm{X}_{11}$ & $(0.1,0.9)$ & 0.4 & 0.6 & 0 & 0 & 0 & 0 & 0 \\
$\mathrm{X}_{12}$ & $(0.4,0.55)$ & 0 & 0 & 0.455 & 0.505 & 0 & 0 & 0 \\
$\mathrm{X}_{13}$ & $(0.05,0.9)$ & 0.657 & 0.303 & 0 & 0 & 0 & 0 & 0 \\
$\mathrm{X}_{14}$ & $(0.05,0.8)$ & 0.569 & 0.311 & 0 & 0 & 0 & 0 & 0 \\
$\mathrm{X}_{21}$ & $(0.3,0.2)$ & 0 & 0 & 0 & 0.24 & 0.36 & 0 & 0 \\
$\mathrm{X}_{22}$ & $(0.3,0.7)$ & 0 & 0.2 & 0.8 & 0 & 0 & 0 & 0 \\
$\mathrm{X}_{23}$ & $(0.1,0.5)$ & 0 & 0.68 & 0 & 0 & 0 & 0 & 0 \\
$\mathrm{X}_{24}$ & $(0.4,0.6)$ & 0 & 0 & 0.6 & 0.4 & 0 & 0 & 0 \\
$\mathrm{X}_{25}$ & $(0.4,0.4)$ & 0 & 0 & 0 & 0.84 & 0 & 0 & 0 \\
$\mathrm{X}_{31}$ & $(0.2,0.7)$ & 0 & 0.613 & 0.307 & 0 & 0 & 0 & 0 \\
$\mathrm{X}_{32}$ & $(0.1,0.8)$ & 0.307 & 0.613 & 0 & 0 & 0 & 0 & 0 \\
$\mathrm{X}_{41}$ & - & - & - & - & - & - & - & - \\
$\mathrm{X}_{42}$ & $(0.4,0.5)$ & 0 & 0 & 0.307 & 0.613 & 0 & 0 & 0 \\
$\mathrm{X}_{43}$ & $(0.6,0.15)$ & 0 & 0 & 0 & 0 & 0.16 & 0.64 & 0 \\
$\mathrm{X}_{44}$ & - & - & - & - & - & - & - & - \\
$\mathrm{X}_{51}$ & $(0.4,0.5)$ & 0 & 0 & 0.307 & 0.613 & 0 & 0 & 0 \\
$\mathrm{X}_{52}$ & $(0.8,0.1)$ & 0 & 0 & 0 & 0 & 0 & 0.613 & 0.307 \\
$\mathrm{X}_{61}$ & $(0.3,0.6)$ & 0 & 0 & 0.92 & 0 & 0 & 0 & 0 \\
$\mathrm{X}_{62}$ & $(0.7,0.2)$ & 0 & 0 & 0 & 0 & 0.307 & 0.613 & 0 \\
$\mathrm{X}_{63}$ & $(0.5,0.3)$ & 0 & 0 & 0 & 0.21 & 0.63 & 0 & 0 \\
$\mathrm{X}_{64}$ & $(0.8,0.15)$ & 0 & 0 & 0 & 0 & 0 & 0.909 & 0.051 \\
$\mathrm{X}_{71}$ & - & - & - & - & - & - & - & - \\
$\mathrm{X}_{72}$ & $(0.1,0.8)$ & 0.307 & 0.613 & 0 & 0 & 0 & 0 & 0 \\
$\mathrm{X}_{73}$ & - & - & - & - & - & - & - & - \\
\hline
\end{tabular}

Next, obtained belief structures are aggregated for each expert and alternative. Belief degrees for each criterion are calculated using Eq. (25). The importance value of criteria derived by IFAHP is used as calculated in the previous section. For instance, for expert 2 and alternative 1, the belief degree at $s_{2}$ level is calculated as:

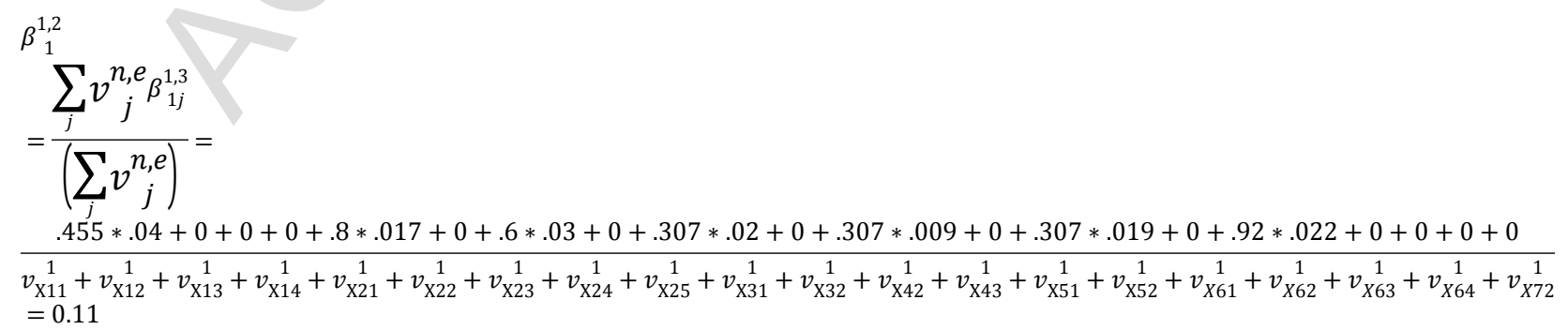


Notice that, since expert 2 did not make a judgment owing to the lack of information, $\beta_{i j}^{e k}$ is considered to be equal to 0 for each $k$. Therefore, they have no effect on the calculation of CBDs. With similar operations for the remaining intuitionistic fuzzy evaluations, the belief structure of expert 2 related to alternative 1 for the Reference scenario is constructed as $B_{1}^{2}=$ $\left\{\left(0.15, s_{0}\right),\left(0.24, s_{1}\right),\left(0.11, s_{2}\right),\left(0.10, s_{3}\right),\left(0.08, s_{4}\right),\left(0.21, s_{5}\right),\left(0.02, s_{6}\right)\right\}$. The results of all experts for petroleum products alternative with respect to this scenario are given in Table 12.

Table 12. Belief degrees and CBDs for petroleum products in the Reference scenario.

\begin{tabular}{llllllll}
\hline \multicolumn{7}{c}{ Belief Degrees } \\
Experts & $\mathrm{S}_{0}$ & $\mathrm{~S}_{1}$ & $\mathrm{~S}_{2}$ & $\mathrm{~S}_{3}$ & $\mathrm{~S}_{4}$ & $\mathrm{~S}_{5}$ & $\mathrm{~S}_{6}$ \\
\hline Expert 1 & 0.01 & 0.27 & 0.25 & 0.09 & 0.08 & 0.12 & 0.02 \\
Expert 2 & 0.15 & 0.24 & 0.11 & 0.10 & 0.08 & 0.21 & 0.02 \\
Expert 3 & 0.10 & 0.18 & 0.16 & 0.23 & 0.16 & 0.03 & 0.00 \\
Expert 4 & 0.07 & 0.19 & 0.13 & 0.17 & 0.15 & 0.13 & 0.08 \\
Expert 5 & 0.01 & 0.22 & 0.13 & 0.17 & 0.14 & 0.15 & 0.06 \\
Expert 6 & 0.03 & 0.19 & 0.25 & 0.11 & 0.07 & 0.19 & 0.08 \\
Expert 7 & 0.02 & 0.20 & 0.18 & 0.16 & 0.21 & 0.12 & 0.03 \\
Expert 8 & 0.10 & 0.12 & 0.24 & 0.12 & 0.04 & 0.11 & 0.27 \\
Expert 9 & 0.25 & 0.14 & 0.00 & 0.14 & 0.08 & 0.16 & 0.23 \\
Expert 10 & 0.00 & 0.15 & 0.18 & 0.37 & 0.13 & 0.17 & 0.00 \\
Expert 11 & 0.16 & 0.22 & 0.04 & 0.05 & 0.13 & 0.18 & 0.12 \\
Expert 12 & 0.00 & 0.05 & 0.05 & 0.10 & 0.14 & 0.30 & 0.16 \\
\hline
\end{tabular}

\begin{tabular}{lllllll}
\hline \multicolumn{7}{l}{ Cumulative Belief Degrees } \\
$\mathrm{S}_{0}$ & $\mathrm{~S}_{1}$ & $\mathrm{~S}_{2}$ & $\mathrm{~S}_{3}$ & $\mathrm{~S}_{4}$ & $\mathrm{~S}_{5}$ & $\mathrm{~S}_{6}$ \\
\hline 0.83 & 0.82 & 0.55 & 0.31 & 0.22 & 0.14 & 0.02 \\
0.91 & 0.76 & 0.53 & 0.42 & 0.31 & 0.23 & 0.02 \\
0.85 & 0.76 & 0.58 & 0.42 & 0.19 & 0.04 & 0.00 \\
0.91 & 0.85 & 0.66 & 0.53 & 0.36 & 0.21 & 0.08 \\
0.88 & 0.88 & 0.66 & 0.53 & 0.35 & 0.22 & 0.06 \\
0.92 & 0.89 & 0.70 & 0.45 & 0.34 & 0.27 & 0.08 \\
0.91 & 0.90 & 0.70 & 0.52 & 0.36 & 0.15 & 0.03 \\
1.00 & 0.90 & 0.78 & 0.54 & 0.42 & 0.39 & 0.27 \\
1.00 & 0.75 & 0.61 & 0.61 & 0.47 & 0.40 & 0.23 \\
1.00 & 1.00 & 0.85 & 0.67 & 0.30 & 0.17 & 0.01 \\
0.89 & 0.73 & 0.51 & 0.47 & 0.43 & 0.30 & 0.12 \\
0.81 & 0.81 & 0.76 & 0.71 & 0.60 & 0.46 & 0.16 \\
\hline
\end{tabular}

Obtained belief degrees were then used to calculate CBDs for each alternative using Eq. (26). For expert 1 and petroleum products in the Reference scenario, as an example, CBD at $s_{4}$ level is calculated as:

$$
\gamma_{1}^{1,4}=\sum_{p=4}^{6} \beta_{1}^{1 p}=\beta_{1}^{1,4}+\beta_{1}^{1,5}+\beta_{1}^{1,6}=0.02+0.12+0.08=0.22
$$

In this way, cumulative belief structure for expert 1 related to petroleum products is found to be $C_{1}^{1}=\left\{\left(0.83, s_{0}\right),\left(0.82, s_{1}\right),\left(0.55, s_{2}\right),\left(0.31, s_{3}\right),\left(0.22, s_{4}\right),\left(0.14, s_{5}\right),\left(0.02, s_{6}\right)\right\}$. The complete CBDs of all experts for petroleum products is provided in Table 12.

Finally, to prioritize alternatives, the CBDs related to expert evaluations given in Table 12 are aggregated for each alternative, also represented as cumulative belief structures. The relative importance of experts is taken into account in Eq. (27) for aggregation. As an example, for petroleum products, $\mathrm{CBD}$ at $s_{5}$ level is calculated as:

$$
\begin{aligned}
& =\sum_{e=1}^{12} \lambda_{e} \gamma_{1}^{e, 5}=0.12 * .0925+0.21 * .0437+0.03 * .0925+0.13 * .1351+0.15 * .0925+0.19 * .0437+0.12 * .0925 \\
& +0.11 * .0437+0.16 * .0437+0.17 * .1351+0.18 * 0925+0.30 * 0925=0.228
\end{aligned}
$$

With similar calculations, cumulative belief structures for the first alternative in the Reference Scenario are calculated to be $C_{1}=$ 
$\left\{\left(0.905, s_{0}\right),\left(0.846, s_{1}\right),\left(0.665, s_{2}\right),\left(0.524, s_{3}\right),\left(0.356 s_{4}\right),\left(0.228, s_{5}\right),\left(0.074, s_{6}\right)\right\}$. CBDs of all the alternatives for the Reference scenario as well as the other scenarios are provided in Table 13 and presented in Fig. 9.

Table 13. CBDs of the alternatives for scenarios.

\begin{tabular}{|c|c|c|c|c|c|c|c|c|}
\hline \multirow{2}{*}{ Scenario } & \multirow{2}{*}{ Alternative } & \multicolumn{7}{|c|}{ CBDs at linguistic-cut levels (rank) } \\
\hline & & $\mathbf{S}_{\mathbf{0}}$ & $\mathbf{S}_{1}$ & $\mathbf{S}_{2}$ & $\mathbf{S}_{\mathbf{3}}$ & $\mathbf{S}_{4}$ & $\mathrm{~S}_{5}$ & $S_{6}$ \\
\hline \multirow{5}{*}{$\begin{array}{l}\text { Reference } \\
\text { scenario (I) }\end{array}$} & Petroleum products & 0.905 & 0.846 & $0.665(5)$ & $0.524(5)$ & $0.356(5)$ & $0.228(5)$ & 0.074 \\
\hline & Crude oil & 0.930 & 0.881 & $0.819(4)$ & $0.696(3)$ & $0.522(3)$ & $0.413(2)$ & 0.163 \\
\hline & Electricity & 0.909 & 0.881 & $0.843(2)$ & $0.759(2)$ & $0.633(2)$ & $0.412(3)$ & 0.100 \\
\hline & Gasoline & 0.896 & 0.883 & $0.84(3)$ & $0.688(4)$ & $0.498(4)$ & $0.292(4)$ & 0.056 \\
\hline & Natural gas & 0.910 & 0.881 & $0.85(1)$ & $0.786(1)$ & $0.716(1)$ & $0.601(1)$ & 0.187 \\
\hline \multirow{6}{*}{$\begin{array}{l}\text { Superego meets } \\
\text { stability (II) }\end{array}$} & & $\mathbf{S}_{\mathbf{0}}$ & $\mathbf{S}_{1}$ & $\mathbf{S}_{2}$ & $\mathbf{S}_{3}$ & $\mathbf{S}_{4}$ & $\mathbf{S}_{5}$ & $S_{6}$ \\
\hline & Petroleum products & 0.911 & 0.895 & $0.779(5)$ & $0.58(5)$ & $0.409(5)$ & $0.252(5)$ & 0.078 \\
\hline & Crude oil & 0.932 & 0.914 & $0.854(2)$ & $0.726(3)$ & $0.562(3)$ & $0.484(2)$ & 0.174 \\
\hline & Electricity & 0.914 & 0.870 & $0.795(4)$ & $0.709(4)$ & $0.596(2)$ & $0.349(4)$ & 0.086 \\
\hline & Gasoline & 0.900 & 0.887 & $0.851(3)$ & $0.748(2)$ & $0.561(4)$ & $0.376(3)$ & 0.074 \\
\hline & Natural gas & 0.913 & 0.887 & $0.855(1)$ & $0.787(1)$ & $0.701(1)$ & $0.583(1)$ & 0.178 \\
\hline \multirow{6}{*}{$\begin{array}{l}\text { After the storm } \\
\text { (III) }\end{array}$} & & $\mathbf{S}_{\mathbf{0}}$ & $\mathbf{S}_{1}$ & & $\mathbf{S}_{\mathbf{3}}$ & $\mathbf{S}_{4}$ & $\mathbf{S}_{5}$ & $S_{6}$ \\
\hline & Petroleum products & 0.904 & 0.893 & $0.802(5)$ & $0.648(5)$ & $0.472(5)$ & $0.316(5)$ & 0.094 \\
\hline & Crude oil & 0.925 & 0.908 & $0.845(1)$ & $0.73(2)$ & $0.55(3)$ & $0.462(2)$ & 0.167 \\
\hline & Electricity & 0.904 & 0.865 & $0.818(4)$ & $0.706(3)$ & $0.585(2)$ & $0.335(3)$ & 0.093 \\
\hline & Gasoline & 0.904 & 0.88 & $0.821(3)$ & $0.692(4)$ & $0.512(4)$ & $0.33(4)$ & 0.058 \\
\hline & Natural gas & 0.909 & 0.886 & $0.839(2)$ & $0.745(1)$ & $0.662(1)$ & $0.559(1)$ & 0.190 \\
\hline \multirow{6}{*}{$\begin{array}{l}\text { All coming } \\
\text { back (IV) }\end{array}$} & & $\mathbf{S}_{0}$ & $\mathbf{S}_{1}$ & & $\mathbf{S}_{3}$ & $\mathbf{S}_{4}$ & $\mathbf{S}_{5}$ & $S_{6}$ \\
\hline & Petroleum products & 0.896 & 0.827 & $0.642(5)$ & $0.465(5)$ & $0.284(5)$ & $0.185(5)$ & 0.068 \\
\hline & Crude oil & 0.939 & 0.869 & $0.788(4)$ & $0.601(4)$ & $0.409(4)$ & $0.299(3)$ & 0.091 \\
\hline & Electricity & 0.888 & 0.878 & $0.861(2)$ & $0.78(2)$ & $0.648(2)$ & $0.422(2)$ & 0.106 \\
\hline & Gasoline & 0.873 & 0.866 & $0.832(3)$ & $0.625(3)$ & $0.434(3)$ & $0.242(4)$ & 0.049 \\
\hline & Natural gas & 0.920 & 0.897 & $0.876(1)$ & $0.845(1)$ & $0.759(1)$ & $0.586(1)$ & 0.167 \\
\hline
\end{tabular}

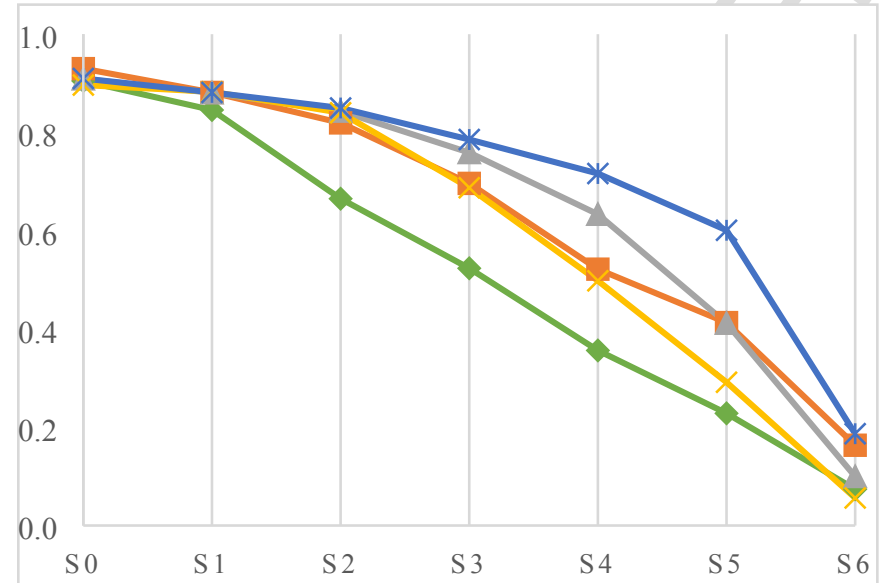

Reference scenario (I)

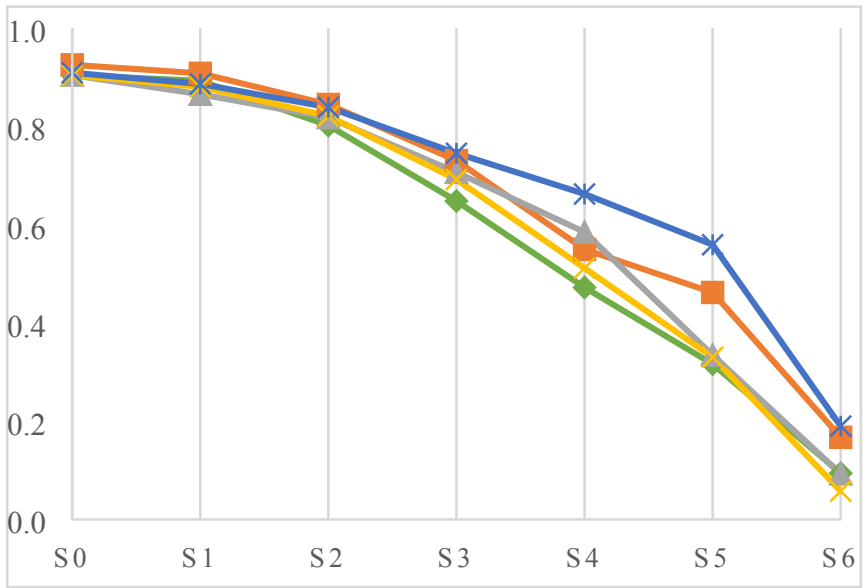

Superego meets stability (II) 


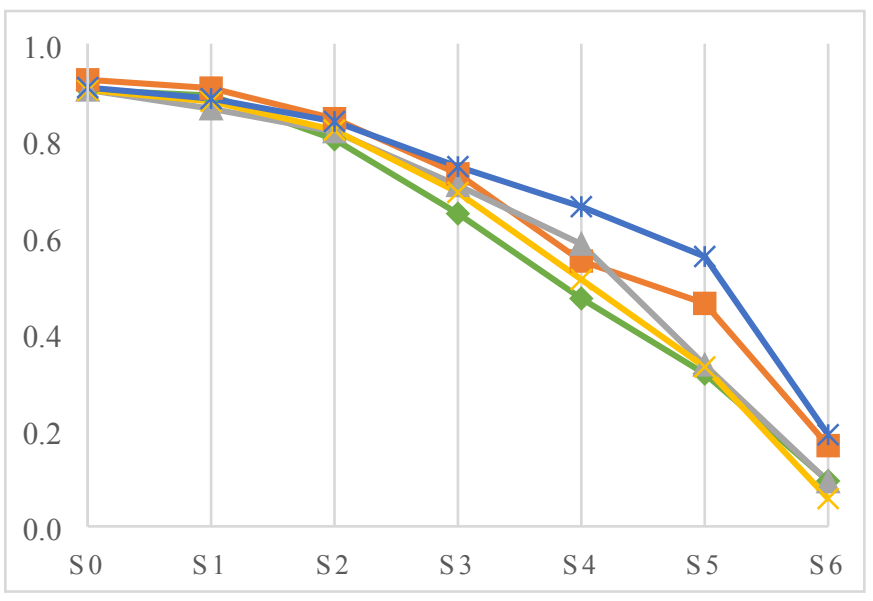

After the storm (III)

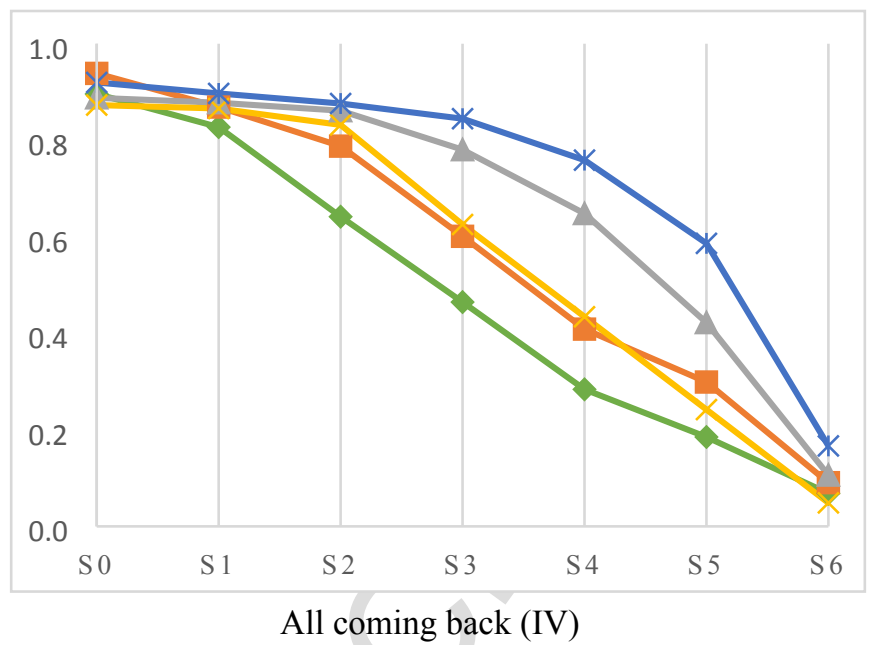

All coming back (IV)

$\smile$ Petroleum products $\leftrightharpoons$ Crude oil $\simeq$ Electricity $\longleftarrow$ Gasoline $\longleftarrow$ Natural gas

Fig. 9. Comparison of the energy alternatives.

To find collective preferences, the aggregated score for each alternative is calculated using Eq. (28). As an example, the aggregated score of natural gas is obtained as follows:

$A S_{4}$

$$
\begin{aligned}
& =\left(\sum_{k=0}^{K-1} v_{k}\left(\gamma_{4}^{k}-\gamma_{4}^{k+1}\right)\right)+v_{K} \gamma_{4}^{K}=0 \cdot(0.91-0.881)+1 \cdot(0.881-0.85)+2 \\
& \cdot(0.85-0.786)+3 \cdot(0.786-0.716)+4 \cdot(0.716-0.601)+5 \cdot(0.601-0.187) \\
& +6 \cdot 0.187=4.021
\end{aligned}
$$

Where expectation values are considered as $v_{k}=k, k=0, \ldots, 6$. Complete aggregated scores of all alternatives are provided in Table 14.

Table 14. Aggregated scores for scenarios.

\begin{tabular}{ccccc}
\hline \multirow{2}{*}{ Alternative } & $\begin{array}{c}\text { Aggregated Scores (rank) } \\
\text { Reference } \\
\text { scenario (I) }\end{array}$ & $\begin{array}{c}\text { Superego meets } \\
\text { stability (II) }\end{array}$ & $\begin{array}{c}\text { After the storm } \\
\text { (III) }\end{array}$ & $\begin{array}{c}\text { All coming back } \\
\text { (IV) }\end{array}$ \\
\hline Petroleum products & $2.693(5)$ & $2.992(5)$ & $3.225(5)$ & $2.471(5)$ \\
Crude oil & $3.495(3)$ & $3.714(2)$ & $3.662(2)$ & $3.056(3)$ \\
Electricity & $3.628(2)$ & $3.405(4)$ & $3.402(3)$ & $3.696(2)$ \\
Gasoline & $3.256(4)$ & $3.497(3)$ & $3.293(4)$ & $3.048(4)$ \\
Natural gas & $4.021(1)$ & $3.991(1)$ & $3.882(1)$ & $4.130(1)$ \\
\hline
\end{tabular}

In the linguistic-cut approach, rank order of the alternatives is found for a selected linguistic level. For instance, if the threshold level is determined as $s_{3}$, then the scores of the alternatives in the Reference Scenario are found based on Eq. (29) as follows: 


$$
L C_{1}^{3}=\gamma_{1}^{3}=0.524, \quad L C_{2}^{3}=\gamma_{2}^{3}=0.696, \quad L C_{3}^{3}=\gamma_{3}^{3}=0.759, \quad L C_{4}^{3}=\gamma_{4}^{3}=0.688, \quad L C_{5}^{3}=\gamma_{5}^{3}=0.786
$$

The scores of the alternatives for the seven linguistic-term levels for the scenarios are given in Table 13. The ranks of the alternatives are also provided for linguistic-terms $s_{2}, s_{3}, s_{4}$, and $s_{5}$.

In the Reference scenario, rankings of the alternatives in the aggregated score approach and linguistic-cut approach at $s_{3}$ and $s_{4}$ level are the same whereas the rankings are slightly different from those in linguistic-cuts $s_{2}$ and $s_{5}$ (see Table 13 and Table 14). Similarly, for the other scenarios, when comparing the results of the aggregate score and linguistic cut levels $s_{2}, s_{3}, s_{4}$, and $s_{5}$, the rankings of the alternatives are almost the same. The first and the last alternatives are always the same while the rankings of the alternatives in the middle change a little.

The results of aggregated score approach and linguistic cut approach at $s_{3}$ level can be used to compare results of the scenarios and to check the validity of the outcome. The results suggest scenarios I\&III maintain the same level, however, electricity and crude oil in Superego meets stability (II) and gasoline and crude oil in All coming back (IV) are replaced. It resulted in relatively same outputs except for Superego meets stability (II), which proposed switching between gasoline and crude oil as the second export option to guarantee Iran's EES. As a result of the comparison of the results for the different approaches, it is fair to conclude that the results of the methodology are robust.

\section{Results}

To interpret the results of the scenarios, energy alternatives are ranked according to the aggregated score approach. Since the results are very similar and it was not possible to select one of the linguistic-cut levels, the aggregated scores of the alternatives are used for further interpretation. In the Reference scenario (I), the alternatives are ranked as natural gas $>$ electricity $>$ crude oil $>$ gasoline $>$ petroleum products (see Table 14Table 14 and Fig. 10). Natural gas remains the top-ranked alternative for Iran's EES in Superego meets stability (II). The ranking of the other alternatives is crude oil $>$ gasoline $>$ electricity $>$ petroleum products. Compared to the Reference scenario (I), electricity falls to the fourth place from second whereas crude oil and gasoline notably overtake electricity. This implies advanced project developments and transferring updated technology in the upstream oil projects (in especially shared fields such as South Pars) through foreign investment in a more stable political condition would shift the attention away from electricity industry. Interestingly, this will not positively affect the exports of petroleum products. 


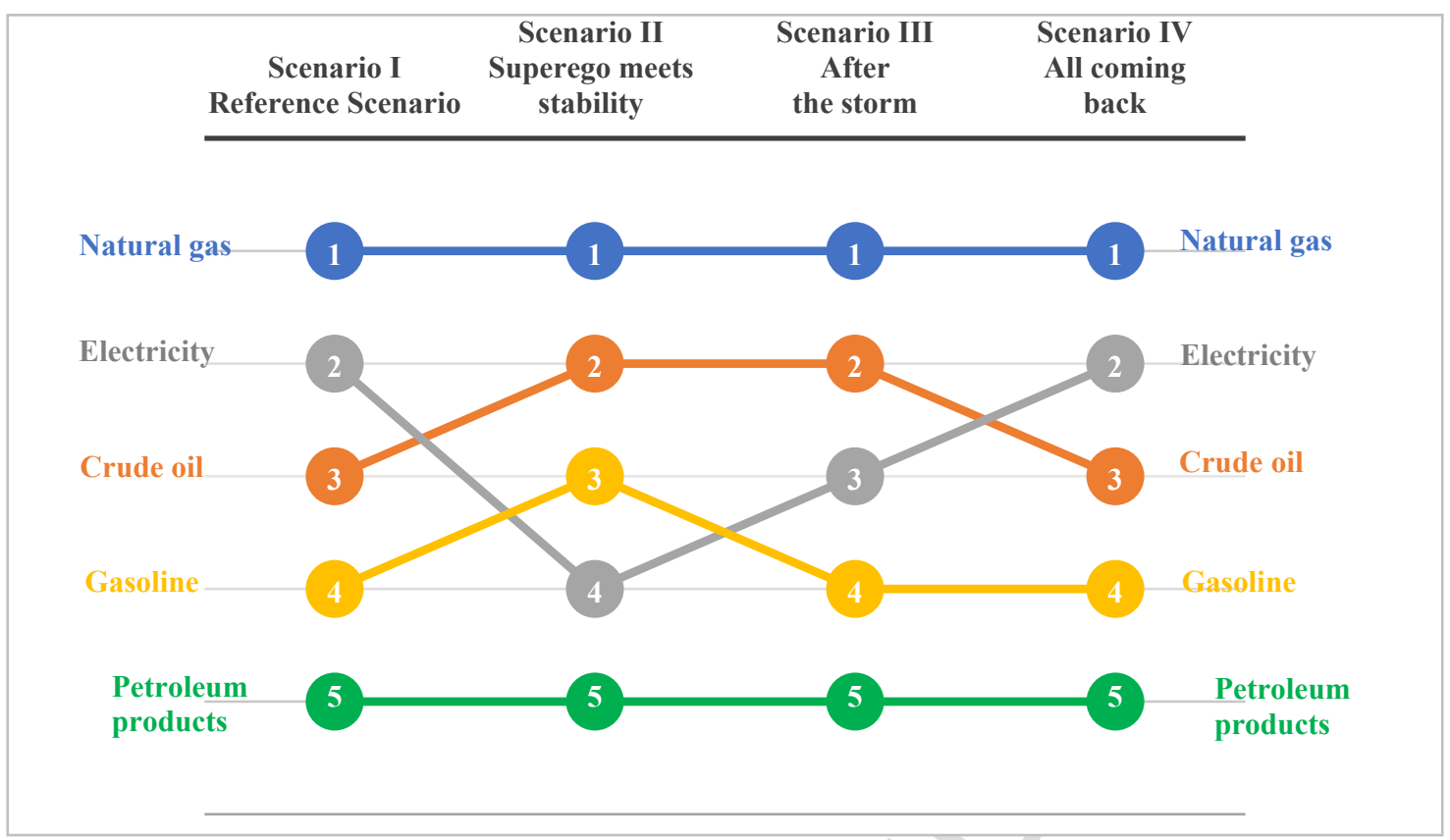

Fig. 10. Ranking of the alternatives using the aggregated score approach for each scenario.

As for After the storm (III), the alternatives are ranked as natural gas $>$ crude oil $>$ electricity $>$ gasoline $>$ petroleum products. In this best imaginable scenario for Iran's energy sector, electricity gains a higher rank than gasoline, primarily owing to the higher degree of international collaboration as well as the favorable condition of RE deployment. The ranking order for All coming back (IV) is the same as the first projection. Both scenarios experience a significant degree of uncertainty in the future of fossil fuels. Under such circumstances when the major part of primary fuels production are used to address the increasing energy consumption trend, the exports of electricity generated by fossil fuels seems a more robust option to deploy than crude oil and gasoline.

In general, natural gas ranked as the most sustainable alternative to supporting Iran's EES in all scenarios. Electricity stands in second place in two scenarios and crude oil ranked higher in scenarios the country witnesses a more stable political situation. These two alternatives and gasoline show sensitivity to different conditions while petroleum products alternative is invariably treated as the last priority. The latter is the least flexible option that is fragile to geopolitical shifts, and simultaneously, confronts the challenges of high domestic demand and outdated technologies. Except for Superego meets stability (II), gasoline took the fourth spot, which can be attributed to the need for high financial and technological support to provide a sustainable alternative in the EES portfolio.

\subsection{Sensitivity analysis}

The developed scenarios produced plausible, and in some cases, similar criteria weights (e.g., low level of influence for social and environmental). To further explore the sensitivity of the result, wild card analysis introduces new specified and nonrandom criteria weights to determine changes in the ranking order of the alternatives. A wild card refers to an unforeseen occurrence that would have large consequences if it takes place. In future studies, it becomes important to add some of these possibilities since they often do reshape the trajectories of situations. 
Here, six wild cards are generated against those four scenarios by changing the weights of main criteria (Table 15). The first three examine the sensitivity of the alternatives to changes in each of the $\mathrm{X}_{3}-\mathrm{X}_{5}$, which received relatively low priorities in the scenarios. Wild cards $4 \& 5$ assume conditions when the two most significant factors for Iran's energy sector simultaneously receive the highest or lowest priorities. Analyzing alternatives if robustness is the main evaluation criteria (or uncertainty is in its highest state) is also tested in the last wild card.

Table 15. Criteria weights of six wild cards to explore the sensitivity of ranking.

\begin{tabular}{lccccccc}
\hline Wild card & \multicolumn{9}{l}{ Criteria weight } & \multicolumn{1}{c}{} \\
\cline { 2 - 8 } & $\mathrm{X}_{1}$ & $\mathrm{X}_{2}$ & $\mathrm{X}_{3}$ & $\mathrm{X}_{4}$ & $\mathrm{X}_{5}$ & $\mathrm{X}_{6}$ & $\mathrm{X}_{7}$ \\
\hline Wild card 1 & 0.1 & 0.1 & 0.4 & 0.1 & 0.1 & 0.1 & 0.1 \\
Wild card 2 & 0.1 & 0.1 & 0.1 & 0.4 & 0.1 & 0.1 & 0.1 \\
Wild card 3 & 0.1 & 0.1 & 0.1 & 0.1 & 0.4 & 0.1 & 0.1 \\
Wild card 4 & 0.25 & 0.25 & 0.1 & 0.1 & 0.1 & 0.1 & 0.1 \\
Wild card 5 & 0.05 & 0.05 & 0.18 & 0.18 & 0.18 & 0.18 & 0.18 \\
Wild card 6 & 0.1 & 0.1 & 0.1 & 0.1 & 0.1 & 0.1 & 0.4 \\
\hline
\end{tabular}

The outcome of the sensitivity analysis using CDB and based on the aggregated score approach are provided in Table 16. According to the results, wild cards produce three different ranking orders compared to the developed scenarios. Out of these, the outcome of wild cards $4 \& 6$ is the same as scenarios I\&IV, wild card 1 is like After the storm (III), and there is no similarity between any wild card and Superego meets stability (II) results. The wild card patterns for natural gas denotes its high priority in three wild cards although its top position is well affected by shifts in weighing in three others. Gasoline stands fourth in most cases except for one while petroleum products alternative is perceived as the last alternative in all cases. Crude oil and electricity are the two more influenced options by acquiring the first rank in three wild cards among them. In general, the ranking is sensitive to the legal and environmental aspects but shows stability when highlighting the importance of social aspect. A simultaneous growth in the political and economic aspects hands the same result as the Reference scenario (I), however, their low priorities lead to a change in the overall ranking.

Table 16. The results of sensitivity analysis.

\begin{tabular}{llccccc}
\hline \multirow{2}{*}{ Wild card } & & Alternative & & & & \\
\cline { 3 - 6 } & & $\begin{array}{c}\text { Petroleum } \\
\text { products }\end{array}$ & Crude oil & Electricity & Gasoline & Natural gas \\
\hline Wild card 1 & Aggregated score & 2.487 & 3.796 & 3.725 & 3.569 & 3.875 \\
& Rank & 5 & 2 & 3 & 4 & 1 \\
Wild card 2 & Aggregated score & 2.912 & 3.934 & 3.427 & 3.653 & 3.778 \\
& Rank & 5 & 1 & 4 & 3 & 2 \\
Wild card 3 & Aggregated score & 3.034 & 3.629 & 3.635 & 3.512 & 3.530 \\
& Rank & 5 & 2 & 1 & 4 & 3 \\
Wild card 4 & Aggregated score & 2.762 & 3.409 & 3.584 & 3.302 & 3.974 \\
& Rank & 5 & 3 & 2 & 4 & 1 \\
Wild card 5 & Aggregated score & 2.823 & 3.844 & 3.563 & 3.544 & 3.726 \\
& Rank & 5 & 1 & 3 & 4 & 2 \\
Wild card 6 & Aggregated score & 2.577 & 3.479 & 3.760 & 3.402 & 3.974 \\
& Rank & 5 & 3 & 2 & 4 & 1 \\
\hline
\end{tabular}




\subsection{Comparison study}

A comparative analysis is conducted to examine the consistency of the results for the Reference scenario. Here, two methods consist of modified FAHP [78] and intuitionistic fuzzy TOPSIS [79] are applied and compared with the results obtained from CBD. Experts were asked to fill in the cells that were left empty during the $\mathrm{CBD}$ evaluation. The preferential ranking is calculated using weights of the criteria collected from Table 8 . The new ranking of the alternatives is presented in Fig. 11.

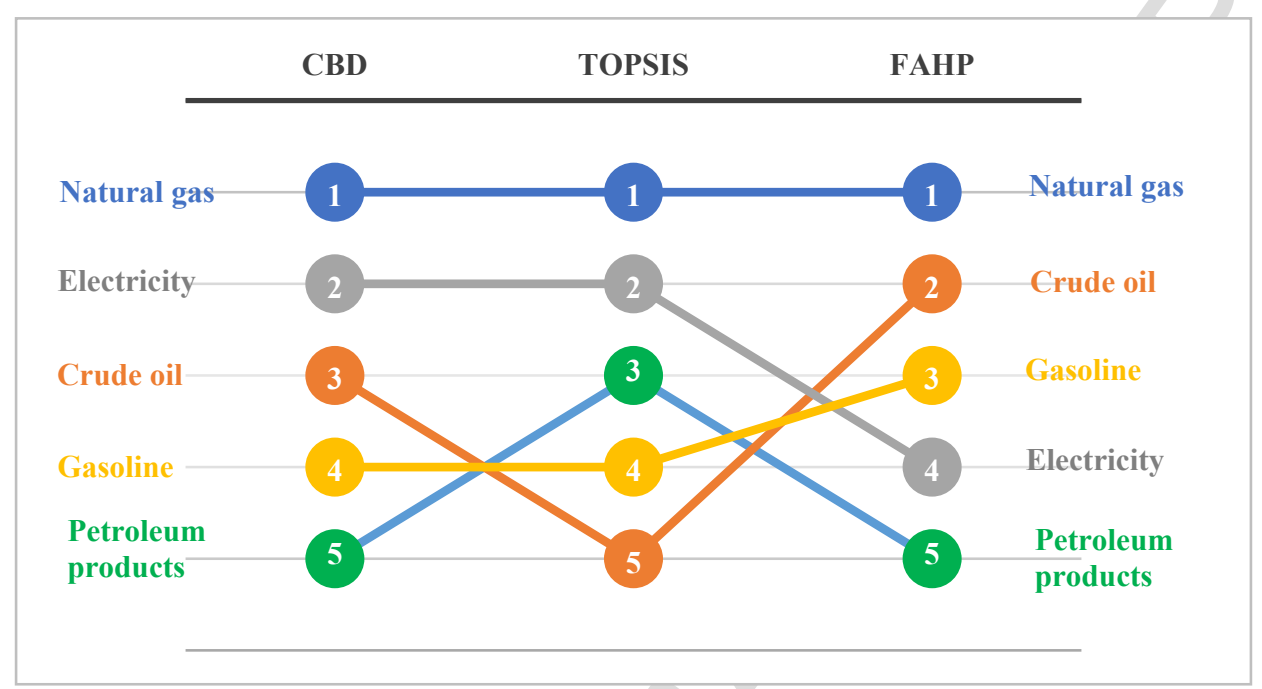

Fig. 11. Comparative ranking of alternatives for the Reference scenario using three MCDM methods.

According to the results, natural gas remains as the leading choice in both methods; crude oil stands last in TOPSIS, but is only second to natural gas in FAHP. In general, despite switching the ranking of petroleum products and crude oil, the results obtained from TOPSIS are mostly consistent and well-coordinated. However, FAHP yields more different ranking orders, with only the first and fifth alternatives are ranked the same as CBD. These differences in the ranking orders can be attributed to the added judgments by experts to fill in the cell that was left empty during the CBD evaluations. Both FAHP and intuitionistic fuzzy TOPSIS required filling all cells for evaluations, cells of which was supposed to be filled only when an expert feel eligible during the CBD process.

\section{Conclusion}

This study proposed a hybrid IFAHP and CBD-based model that addresses inherent uncertainties exist in MCDM problems. It has the benefits of a comprehensive analyzing approach and uncovers all involved criteria through PESTLE analysis. The model deals with the uncertainties through IFSs, robust parameters, and scenario planning. The latter is at the heart of the proposed framework where the MCDM model was implemented based on plausible scenarios, and sensitivity analysis was built on actual wild cards rather than random manipulations in criteria weights.

From an energy planning point of view, this research was one of the first attempts to investigate EES as an arising issue in the global energy market. Its importance comes from the fact that guaranteeing EES can strongly affect suppliers' bargaining power and market shares. Applying 
the model to Iran as a case study, robustness was the dominant criteria for the Reference scenario while technological, economic, and political factors were superior in other scenarios. Social, legal and environmental factors also showed less sensitivity in different cases. Prioritization of alternatives through CBD illustrated that natural gas had the highest priority in all scenarios. Electricity, oil, and gasoline fluctuate between second and fourth, with each may have a high (second best option) or a low priority (second worst option) depending on the scenario circumstances. Conversely, petroleum products alternative which came as the lowest priority in all scenarios is least influenced by variations in the country's energy sector.

This research can be further extended by analyzing causal impacts of EES policy conducted in this work, diversification of energy generation and raising fossil fuels to their full cost price on each other. Analyzing their dynamic behaviors may provide extensive interpretations of what the future could hold. The focus of the proposed framework was to deal with uncertainties in the energy sector. It can be used in other MCDM problems facing such challenges. Other well-known weight assessment approaches in intuitionistic or hesitant fuzzy environments might also be employed to synthesize with CBD and derive criteria weights, and then be compared with the results of this work.

\section{References}

1. Hafeznia, H., F. Pourfayaz, and A. Maleki, An assessment of Iran's natural gas potential for transition toward low-carbon economy. Renewable and Sustainable Energy Reviews, 2017. 79: p. 71-81.

2. Chaharsooghi, S., M. Rezaei, and M. Alipour, Iran's energy scenarios on a 20-year vision. International Journal of Environmental Science and Technology, 2015. 12(11): p. 37013718 .

3. Alipour, M., et al., A new hybrid decision framework for prioritizing funding allocation to Iran's energy sector. Energy, 2017. 121: p. 388-402.

4. Sadeghi, M. and H.M. Hosseini, Energy supply planning in Iran by using fuzzy linear programming approach (regarding uncertainties of investment costs). Energy policy, 2006. 34(9): p. 993-1003.

5. Alipour, M. and A. Sheykhan, A vision for Iran's fuel cell and hydrogen development. International Journal of Environmental Science and Technology, 2017. 14(1): p. 193-210.

6. Abbaszadeh, P., et al., Iran's oil development scenarios by 2025. Energy policy, 2013. 56: p. 612-622.

7. Team, F., PESTLE Analysis. Strategy Skills. Ebook: http://www.free-managementebooks.com/dldebk-pdf/fme-pestle-analysis.pdf, 2013.

8. Kabak, Ö., D. Cinar, and G.Y. Hoge, A cumulative belief degree approach for prioritization of energy sources: case of Turkey, in Assessment and simulation tools for sustainable energy systems. 2013, Springer. p. 129-151.

9. Ervural, B. and Ö. Kabak, A Novel Group Decision Making Approach Based On the Cumulative Belief Degrees. IFAC-PapersOnLine, 2016. 49(12): p. 1832-1837.

10. Tavana, M., et al., An integrated intuitionistic fuzzy AHP and SWOT method for outsourcing reverse logistics. Applied Soft Computing, 2016. 40: p. 544-557.

11. Atanassov, K.T., Intuitionistic fuzzy sets. Fuzzy sets and Systems, 1986. 20(1): p. 87-96.

12. Liao, $\mathrm{H}$. and $\mathrm{Z}$. Xu, Multi-criteria decision making with intuitionistic fuzzy PROMETHEE. Journal of Intelligent \& Fuzzy Systems, 2014. 27(4): p. 1703-1717. 
13. Månsson, A., B. Johansson, and L.J. Nilsson, Assessing energy security: An overview of commonly used methodologies. Energy, 2014. 73: p. 1-14.

14. Sovacool, B.K. and I. Mukherjee, Conceptualizing and measuring energy security: $A$ synthesized approach. Energy, 2011. 36(8): p. 5343-5355.

15. Ang, B.W., W. Choong, and T. Ng, Energy security: Definitions, dimensions and indexes. Renewable and Sustainable Energy Reviews, 2015. 42: p. 1077-1093.

16. Thangavelu, S.R., A.M. Khambadkone, and I.A. Karimi, Long-term optimal energy mix planning towards high energy security and low GHG emission. Applied energy, 2015. 154: p. 959-969.

17. Bilgin, M., Scenarios on European energy security: Outcomes of natural gas strategy in 2020. Futures, 2011. 43(10): p. 1082-1090.

18. Jewell, J., A. Cherp, and K. Riahi, Energy security under de-carbonization scenarios: An assessment framework and evaluation under different technology and policy choices. Energy Policy, 2014. 65: p. 743-760.

19. Stirling, A., Multicriteria diversity analysis: a novel heuristic framework for appraising energy portfolios. Energy Policy, 2010. 38(4): p. 1622-1634.

20. Lee, S.K., G. Mogi, and J.W. Kim, Decision support for prioritizing energy technologies against high oil prices: a fuzzy analytic hierarchy process approach. Journal of Loss Prevention in the Process Industries, 2009. 22(6): p. 915-920.

21. Ren, J. and B.K. Sovacool, Prioritizing low-carbon energy sources to enhance China's energy security. Energy Conversion and Management, 2015. 92: p. 129-136.

22. Ravindra, K. and P.P. Iyer, Decentralized demand-supply matching using community microgrids and consumer demand response: a scenario analysis. Energy, 2014. 76: p. 3241.

23. Zhang, L., et al., Measuring energy security performance within China: Toward an interprovincial prospective. Energy, 2017. 125: p. 825-836.

24. Gao, D., et al., A coordinated energy security model taking strategic petroleum reserve and alternative fuels into consideration. Energy, 2018. 145: p. 171-181.

25. Bompard, E., et al., National energy security assessment in a geopolitical perspective. Energy, 2017. 130: p. 144-154.

26. Zeng, S., D. Streimikiene, and T. Baležentis, Review of and comparative assessment of energy security in Baltic States. Renewable and Sustainable Energy Reviews, 2017. 76: p. 185-192.

27. Mišík, M., On the way towards the Energy Union: Position of Austria, the Czech Republic and Slovakia towards external energy security integration. Energy, 2016. 111: p. 68-81.

28. Vosylius, E., V. Rakutis, and M. Tvaronavičienè, ECONOMIC GROWTH, SUSTAINABLE DEVELOPMENT AND ENERGY SECURITY INTERRELATIONS. Journal of Security \& Sustainability Issues, 2013. 2(3).

29. Baran, Z., EU energy security: time to end Russian leverage. Washington Quarterly, 2007. 30(4): p. 131-144.

30. Goldthau, A. and B.K. Sovacool, The uniqueness of the energy security, justice, and governance problem. Energy Policy, 2012. 41: p. 232-240.

31. Jacobson, M.Z., Review of solutions to global warming, air pollution, and energy security. Energy \& Environmental Science, 2009. 2(2): p. 148-173.

32. Zadeh, L.A., Fuzzy sets. Information and control, 1965. 8(3): p. 338-353. 
33. Szmidt, E. and J. Kacprzyk, Distances between intuitionistic fuzzy sets. Fuzzy sets and systems, 2000. 114(3): p. 505-518.

34. Dubois, D.J., Fuzzy sets and systems: theory and applications. Vol. 144. 1980: Academic press.

35. Li, D.-F., A ratio ranking method of triangular intuitionistic fuzzy numbers and its application to MADM problems. Computers \& Mathematics with Applications, 2010. 60(6): p. 1557-1570.

36. Saaty, T.L., The Analytic Hierarchy Process, NY. McGraw-Hill, USA. Cook WD and Seiford LM.(1978). Priority ranking and consensus formation, Management Science, 1980. 24: p. 1721-1732.

37. Van Laarhoven, P. and W. Pedrycz, A fuzzy extension of Saaty's priority theory. Fuzzy sets and Systems, 1983. 11(1-3): p. 229-241.

38. Chang, D.-Y., Applications of the extent analysis method on fuzzy AHP. European journal of operational research, 1996. 95(3): p. 649-655.

39. Wang, Y.-M., Y. Luo, and Z. Hua, On the extent analysis method for fuzzy AHP and its applications. European Journal of Operational Research, 2008. 186(2): p. 735-747.

40. Sadiq, R. and S. Tesfamariam, Environmental decision-making under uncertainty using intuitionistic fuzzy analytic hierarchy process (IF-AHP). Stochastic Environmental Research and Risk Assessment, 2009. 23(1): p. 75-91.

41. Mikhailov, L. and M.G. Singh, Fuzzy assessment of priorities with application to competitive bidding. Journal of Decision Systems, 1999. 8(1): p. 11-28.

42. Kabak, O. and D. Ruan, A cumulative belief degree-based approach for missing values in nuclear safeguards evaluation. IEEE Transactions on Knowledge and Data Engineering, 2011. 23(10): p. 1441-1454.

43. Ruan, D., Ö. Kabak, and R. Quinones, An ordered weighted averaging operator-based cumulative belief degree approach for energy policy evaluation. International Journal of Advanced Operations Management 11, 2013. 5(1): p. 58-73.

44. Ünlüçay, H., et al., Cumulative Belief Degrees Approach for Assessment of Sustainable Development, in Intelligence Systems in Environmental Management: Theory and Applications. 2017, Springer. p. 257-289.

45. Mikhailov, L., Group prioritization in the AHP by fuzzy preference programming method. Computers \& operations research, 2004. 31(2): p. 293-301.

46. Wu, Y., et al., Study of decision framework of offshore wind power station site selection based on ELECTRE-III under intuitionistic fuzzy environment: A case of China. Energy Conversion and Management, 2016. 113: p. 66-81.

47. BP, statistical review of world energy 2016. 2016, British Petroleum: London, United Kingdom.

48. Hafezi, R., A. Akhavan, and S. Pakseresht, Projecting plausible futures for Iranian oil and gas industries: Analyzing of historical strategies. Journal of Natural Gas Science and Engineering, 2017. 39: p. 15-27.

49. Annual statistical bulletin. 2017, OPEC

50. Kahraman, C. and İ. Kaya, A fuzzy multicriteria methodology for selection among energy alternatives. Expert Systems with Applications, 2010. 37(9): p. 6270-6281.

51. Belke, A., F. Dobnik, and C. Dreger, Energy consumption and economic growth: New insights into the cointegration relationship. Energy Economics, 2011. 33(5): p. 782-789.

52. Youngs, R., Energy security: Europe's new foreign policy challenge. 2009: Routledge. 
53. Sovacool, B.K. and M.A. Brown, Competing dimensions of energy security: an international perspective. Annual Review of Environment and Resources, 2010. 35: p. 77108.

54. Böhringer, C. and M. Bortolamedi, Sense and no (n)-sense of energy security indicators. Ecological Economics, 2015. 119: p. 359-371.

55. Winzer, C., Conceptualizing energy security. Energy policy, 2012. 46: p. 36-48.

56. Shen, W. and M. Power, Africa and the export of China's clean energy revolution. Third World Quarterly, 2017. 38(3): p. 678-697.

57. Westphal, K., Institutional change in European natural gas markets and implications for energy security: Lessons from the German case. Energy policy, 2014. 74: p. 35-43.

58. Lilliestam, J. and S. Ellenbeck, Energy security and renewable electricity trade-Will Desertec make Europe vulnerable to the "energy weapon"? Energy policy, 2011. 39(6): p. 3380-3391.

59. Şengül, Ü., et al., Fuzzy TOPSIS method for ranking renewable energy supply systems in Turkey. Renewable Energy, 2015. 75: p. 617-625.

60. Bhattacharya, A. and S. Kojima, Power sector investment risk and renewable energy: A Japanese case study using portfolio risk optimization method. Energy Policy, 2012. 40: p. 69-80.

61. Bhattacharyya, S.C., Energy economics: concepts, issues, markets and governance. 2011: Springer Science \& Business Media.

62. Bohi, D.R. and M.A. Toman, The economics of energy security. 2012: Springer Science \& Business Media.

63. Stigka, E.K., J.A. Paravantis, and G.K. Mihalakakou, Social acceptance of renewable energy sources: A review of contingent valuation applications. Renewable and Sustainable Energy Reviews, 2014. 32: p. 100-106.

64. Boersma, T., Energy security and natural gas markets in Europe: Lessons from the EU and the United States. 2015: Routledge.

65. Daojiong, Z., China's energy security: Domestic and international issues. Survival, 2006. 48(1): p. 179-190.

66. Franki, V. and A. Višković, Energy security, policy and technology in South East Europe: Presenting and applying an energy security index to Croatia. Energy, 2015. 90: p. 494507.

67. Ren, J. and B.K. Sovacool, Quantifying, measuring, and strategizing energy security: Determining the most meaningful dimensions and metrics. Energy, 2014. 76: p. 838-849.

68. Fernandez, P.M. and I. Soares, Addressing 2030 EU policy framework for energy and climate: Cost, risk and energy security issues. Energy, 2016. 115: p. 1347-1360.

69. Vivoda, V., Evaluating energy security in the Asia-Pacific region: A novel methodological approach. Energy Policy, 2010. 38(9): p. 5258-5263.

70. Chung, W.-S., et al., A conceptual framework for energy security evaluation of power sources in South Korea. Energy, 2017. 137: p. 1066-1074.

71. Alizadeh, R., et al., An integrated scenario-based robust planning approach for foresight and strategic management with application to energy industry. Technological Forecasting and Social Change, 2016. 104: p. 162-171.

72. Gracceva, F. and P. Zeniewski, A systemic approach to assessing energy security in a lowcarbon EU energy system. Applied Energy, 2014. 123: p. 335-348.

73. Yergin, D., Ensuring energy security. Foreign affairs, 2006: p. 69-82. 
74. Moshiri, S., et al., Long run energy demand in Iran: a scenario analysis. International Journal of Energy Sector Management, 2012. 6(1): p. 120-144.

75. Bahrami, M. and P. Abbaszadeh, Development a scenario-based model for Iran's energy future. Renewable and Sustainable Energy Reviews, 2016. 62: p. 963-970.

76. Renewable Energy and Energy Efficiency Organization (SATBA), Iran's ministry of energy. 2009 Accessed 16 August 2017]; Available from: http://www.opec.org/opec web/en/publications/202.htm.

77. Alipour, M., et al., A new hybrid fuzzy cognitive map-based scenario planning approach for Iran's oil production pathways in the post-sanction period. Energy, 2017. 135: p. 851864.

78. Kabir, G. and R.S. Sumi, Power substation location selection using fuzzy analytic hierarchy process and PROMETHEE: a case study from Bangladesh. Energy, 2014. 72: p. 717-730.

79. Chen, S.-M., S.-H. Cheng, and T.-C. Lan, Multicriteria decision making based on the TOPSIS method and similarity measures between intuitionistic fuzzy values. Information Sciences, 2016. 367: p. 279-295. 
- A four-phase decision making framework for robust energy export security planning.

- Incorporation of IFAHP and CBD to prioritize energy export alternatives.

- Scenarios, robustness criteria and intuitionistic fuzzy sets to deal with uncertainties.

- Evaluation of Iran's energy export security policies.

- Natural gas is Iran's best option in all scenarios to secure energy exports. 


\section{Accepted Manuscript}

Long-term policy evaluation: Application of a new robust decision framework for Iran's energy exports security

Mohammad Alipour, Reza Hafezi, Bilal Ervural, Mohamad Amin Kaviani, Özgür

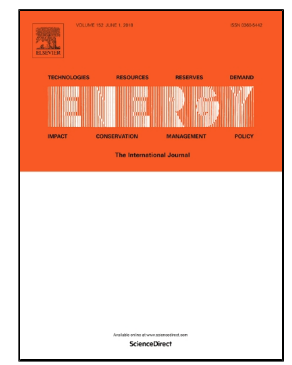
Kabak

PII: S0360-5442(18)31020-X

DOI: 10.1016/j.energy.2018.05.176

Reference: EGY 13011

To appear in: Energy

Received Date: 17 November 2017

Accepted Date: 26 May 2018

Please cite this article as: Mohammad Alipour, Reza Hafezi, Bilal Ervural, Mohamad Amin Kaviani, Özgür Kabak, Long-term policy evaluation: Application of a new robust decision framework for Iran' s energy exports security, Energy (2018), doi: 10.1016/j.energy.2018.05.176

This is a PDF file of an unedited manuscript that has been accepted for publication. As a service to our customers we are providing this early version of the manuscript. The manuscript will undergo copyediting, typesetting, and review of the resulting proof before it is published in its final form. Please note that during the production process errors may be discovered which could affect the content, and all legal disclaimers that apply to the journal pertain. 